\title{
Expectations, Credibility, and Disinflation in a Small Macroeconomic Model*
}

\author{
Chan G. Huh ${ }^{\dagger}$ \\ Federal Reserve Bank of San Francisco \\ Kevin J. Lansing $\ddagger$ \\ Federal Reserve Bank of San Francisco \\ Forthcoming, Journal of Economics and Business \\ First Draft: November 1997 \\ This Draft: June 1, 1999
}

\begin{abstract}
We use a version of the Fuhrer-Moore model to study the effects of expectations and central bank credibility on the economy's dynamic transition path during a disinflation. Simulations are compared under four different specifications of the model that vary according to the way that expectations are formed (rational versus adaptive) and the degree of central bank credibility (full versus partial). The various specifications exhibit qualitatively similar behavior and can reasonably approximate the trend movements in U.S. macro variables during the Volcker disinflation of the early 1980s. However, the specification with adaptive expectations/partial credibility is the only one to capture the temporary rise in long-term nominal interest rates observed in U.S. data at the start of the disinflation. We also show that incremental reductions in the output sacrifice ratio are largest at the low end of the credibility range, suggesting that a central bank may face diminishing returns in its efforts to enhance credibility.
\end{abstract}

Keywords: Monetary Policy, Inflation, Business Cycles.

JEL Classification: E31, E32, E43, E52.

\footnotetext{
${ }^{*}$ We thank Jeff Fuhrer for generously providing us with his computer programs and for assistance in modifying them for this paper. For helpful comments and suggestions, we also thank Timothy Cogley, John Judd, Athanasios Orphanides, Glenn Rudebusch, and seminar participants at FRB Cleveland, the Hoover Institution, the Federal Reserve System Macro Conference (November 1997), and an anonymous referee. Melissa Leung provided excellent research assistance. Part of this research was conducted while Lansing was a national fellow at the Hoover Institution, whose hospitality is gratefully acknowledged. The views in this paper are those of the authors and not necessarily those of the Federal Reserve Bank of San Francisco or of the Federal Reserve System.

${ }^{\dagger}$ Research Department, Federal Reserve Bank of San Francisco, P.O. Box 7702, San Francisco, CA 941207702, email: chan.huh@sf.frb.org

$\ddagger$ Corresponding author. Research Department, Federal Reserve Bank of San Francisco, P.O. Box 7702, San Francisco, CA 94120-7702, ph: (415) 974-2393, Fax: (415) 974-3429, email: kevin.j.lansing@sf.frb.org
} 


\section{Introduction}

The idea that expectations can play a crucial role in determining the effects of monetary policy on real and nominal variables is now a well established paradigm in macroeconomics. ${ }^{1}$ It is also widely recognized that central bank credibility — defined generally as the extent to which beliefs about future policy actions are consistent with the announced programs of policymakers - is an important factor governing the cost of disinflationary policies. ${ }^{2}$ This paper uses a small macroeconomic model to study the effects of expectations and credibility on the economy's dynamic transition path during a disinflation. In particular, we experiment with different assumptions regarding the way that expectations are formed (rational versus adaptive) and the degree of central bank credibility (full versus partial) to determine which of the various specifications can best account for the trend movements in U.S. macro variables during the Volcker disinflation of the early 1980s. We also investigate the implications of these features for the length, speed, and cost of the disinflation episode.

The framework for our analysis is a version of the forward-looking macroeconomic model developed by Fuhrer and Moore (1995a,b). This model is quite tractable and has the advantage of being able to reproduce the dynamic correlations among U.S. inflation, short-term nominal interest rates, and deviations of real output from trend. The model consists of an aggregate demand equation, a nominal wage contracting equation (that embeds a version of an expectations-augmented Phillips curve), a central bank reaction function that defines monetary policy, and a term structure equation. We append a simple version of Okun's law that relates the unemployment rate to the deviation of real output from trend.

The experiment we consider is one in which the central bank announces a program to reduce the prevailing rate of inflation and then immediately embarks on such a path by lowering the target level of inflation in the reaction function. This leads to a monetary contraction, as evidenced by an increase in the short-term nominal interest rate. Due to the presence of nominal rigidities (staggered wage contracts), the tighter monetary policy results in a temporary decline in real output relative to trend and a corresponding increase in the unemployment rate.

A key assumption underlying the use of rational expectations in macroeconomic models is that agents have enough information about the structure of the economy to make unbiased forecasts of the relevant economic variables. Taylor $(1975,1993)$ and Friedman (1979) argue

\footnotetext{
${ }^{1}$ The classic articles include Phelps (1967, 1968), Friedman (1968), Lucas (1972, 1973), Sargent (1973), Sargent and Wallace (1975), Taylor (1975), and Barro (1976).

${ }^{2}$ See, for example, Sargent (1982, 1983), Taylor (1982), and Fischer (1986). For a survey of the (huge) game-theoretic literature on credibility in monetary policy, see Blackburn and Christensen (1989).
} 
that this assumption may be unrealistic during the transition period immediately following a major policy change because agents have not had sufficient time to fully comprehend the implications of the new policy or become convinced of the policymaker's commitment to maintaining it. Such a scenario seems particularly applicable to the Volcker era, given the Fed's adoption in October 1979 of an operating procedure for targeting nonborrowed reserves that was unprecedented. Based on this view, we consider the possibility that agents' forecasts during the transition to lower inflation do not make optimal use of all available information, but instead, are constructed using a first-order vector autoregression (VAR) that involves a subset of known variables. This setup can be viewed as a particular form of adaptive (or distributed lag) expectations. ${ }^{3}$

Regarding credibility, it seems reasonable to assume that the Federal Reserve's commitment to reducing inflation was viewed with considerable skepticism at the start of the Volcker disinflation. Two previous attempts to reduce inflation begun in April 1974 and August 1978 had proven unsuccessful. ${ }^{4}$ Contributing to this skepticism in the period immediately following October 1979 were the large and erratic fluctuations of monetary aggregates (which were frequently outside their target ranges) and the Fed's decision to briefly loosen policy by lowering short-term interest rates from April to June 1980 in the face of growing signs of a recession. ${ }^{5}$ Moreover, U.S. fiscal policy around this time was characterized by large and growing federal budget deficits which, if projected forward, might have been seen to imply the need for future monetization of the debt to maintain solvency of the government's intertemporal budget constraint. ${ }^{6}$

In this paper, we formalize the notion of credibility as agents' subjective probabilistic belief that the central bank's inflation target has been reduced to the new value announced at the start of the disinflation. The true inflation target is assumed to be unobservable due to the presence of exogenous stochastic shocks in the policy reaction function. These policy shocks, together with stochastic disturbances to other parts of the economy, give rise to a distribution of observed inflation rates around any given target level. Under full credibility, the economy is

\footnotetext{
${ }^{3} \mathrm{~A}$ higher-order distributed lag specification (labeled VAR-based expectations) is used in the Federal Reserve Board's large-scale macroeconomic model, known as FRB/US. The Board's model also allows for rational (or model-consistent) expectations. For details, see Brayton, et al. (1997).

${ }^{4}$ See Shapiro (1994) for an analysis of the relative success of Federal Reserve attempts to reduce inflation following seven postwar dates marking the start of an explicit disinflationary policy, as identified by Romer and Romer $(1989,1994)$.

${ }^{5}$ The implementation of credit controls in March 1980 also contributed to the lowering of short-term interests rates during this period. For details on monetary policy in the early 1980s, see Friedman (1984), Blanchard (1984), Hetzel (1986), and Goodfriend (1993).

${ }^{6}$ The crucial importance of the fiscal regime in determining the credibility of disinflationary policies is emphasized by Sargent (1982, 1983). For applications of this idea, see Flood and Garber (1980), Baxter (1985), and Ruge-Murcia (1995).
} 
assumed to be populated by agents who, upon hearing the announcement, assign a probability of one to the event that the inflation target has actually been reduced. These agents continue to assign a probability of one regardless of the time path of inflation that is subsequently observed. In contrast, partial credibility implies that agents update their prior assessment of the true inflation target in a (quasi) Bayesian way on the basis of the central bank's success or failure in reducing inflation over time. Our setup is similar to one used by Meyer and Webster (1982) in which agents' expectations are constructed as a probability-weighted average of the expectations that would prevail under an "old" and "new" policy rule.

Credibility has an important influence on expectations and, therefore, on the dynamics of disinflation. When the central bank enjoys a high degree of prior credibility, rational agents will quickly lower their inflation expectations in response to the announced change in the inflation target. This shift in expectations helps to lower current inflation (via forward-looking wage contracts) and thus contributes to a faster and less costly disinflation episode. In contrast, when prior credibility is low, agents' expectations respond only gradually as they become convinced of the central bank's commitment to reducing inflation. In this case, the transition path involves learning and the use of Bayes rule so that rational expectations can display some of the backward-looking characteristics of traditional adaptive expectations. ${ }^{7}$

Using parameter values estimated over the period 1965:1 to 1996:4, we trace out the economy's dynamic transition path for the different specifications of expectations and credibility described above. The speed at which agents adjust their forecasts in response to the announced policy change varies across specifications. In particular, forecasts adjust quickly with rational expectations/full credibility and slowly with adaptive expectations/partial credibility.

Aside from the speed of response, the various specifications exhibit qualitatively similar behavior and can reasonably approximate the trend movements in U.S. macro variables observed during the Volcker disinflation. An important feature that differentiates the specifications, however, is their prediction regarding the term structure of interest rates. It turns out that the specification with adaptive expectations/partial credibility is the only one to capture the temporary rise in long-term nominal interest rates observed in U.S. data at the start the Volcker disinflation.

The model's term structure is based on the pure expectations hypothesis, that is, the longterm rate is a weighted average of current and expected future short-term rates. When the short rate rises as a result of tighter monetary policy, the implications for the long rate are

\footnotetext{
${ }^{7}$ Other research that applies Bayesian learning to models of monetary policy includes Taylor (1975), Flood and Garber (1980), Backus and Drifill (1985a,b), Barro (1986), Lewis (1989), Baxter (1985, 1989), Bertocchi and Spagat (1993), Gagnon (1997), and Andolfatto and Gomme (1997).
} 
theoretically ambiguous. In particular, upward pressure stemming from the increase in the current short rate may be offset by downward pressure from expectations of lower short rates in the future, due to lower anticipated inflation. Hence, the behavior of the long rate depends crucially on the model's specification of expectations and credibility. ${ }^{8}$

When forecasts adjust slowly to the announced policy change because of adaptive expectations or partial credibility, we find that the central bank undertakes a greater degree of monetary tightening, as measured by the peak level of the short-term nominal interest rate. This is due to the form of the reaction function that makes the short-term interest rate a function of the distance between the current inflation rate (which falls slowly) and the new inflation target. The sluggish adjustment of forecasts also means that a higher level of inflation is built into expectations of future short rates. Both effects combine to raise the level of the current long rate in comparison to specifications where forecasts adjust rapidly. In the specification with adaptive expectations/partial credibility, the inertia built into agents' inflation forecasts is sufficient to cause the long rate to rise in response to the tighter monetary policy. The other three specifications predict a fall in the long rate in response to the tighter policy.

The observation that U.S. long-term interest rates rose during the early stages of the Volcker disinflation suggests, therefore, that market expectations were slow to adjust to the change in Fed policy. A similar conclusion is reached by Blanchard (1984), who analyzes the pattern of term structure forecast errors during this period. The forecasts errors suggest that financial markets did not expect inflation to be lowered rapidly. More generally, the model with adaptive expectations/partial credibility is consistent with the empirical studies of Cook and Hahn (1989), Evans and Marshall (1998), and others, which indicate that tighter monetary policy leads to an increase in long-term nominal interest rates. ${ }^{9}$

Our results also help to provide some insight into the findings of Pagan and Robertson (1995) who show that the 1979-1982 period is a watershed for empirical work that attempts to identify the so-called "liquidity effect" of a monetary policy shock. ${ }^{10}$ The $1979-1982$ period is precisely the time when agents' forecasts would be inclined to adjust slowly as they attempted to decipher the implications of the Fed's new operating procedure. Our model predicts that when forecasts adjust slowly, an exogenous monetary contraction (induced by a lowering of the inflation target) will lead to a more pronounced increase in the short-term nominal interest

\footnotetext{
${ }^{8}$ Fuhrer (1996) shows that the model's term structure is also influenced by structural breaks in the parameters of the central bank reaction function.

${ }^{9}$ Akhtar (1995) surveys the enormous empirical literature that examines the effects of monetary policy on long-term nominal interest rates.

${ }^{10}$ The term "liquidity effect" is typically used describe the idea that an exogenous monetary contraction (expansion) leads to a persistent increase (decrease) in the short-term nominal interest rate and a persistent fall (rise) in the level of real output relative to trend.
} 
rate and a more pronounced fall in real output, i.e., a stronger liquidity effect.

The above discussion highlights an interesting connection between our model and some recently developed dynamic general equilibrium models that are designed to exhibit a liquidity effect. Researchers working with these models have shown that the key to obtaining a liquidity effect is to dampen and/or delay the impact of anticipated inflation on the short-term nominal interest rate in the periods immediately following the shock. Modeling devices that help accomplish this include: restrictions on agents' ability to alter cash holdings (Christiano and Eichenbaum 1992), short-run price stickiness (Ohanian and Stockman 1995), and incomplete information and learning (Andolfatto and Gomme 1997). Similarly, we find that adaptive expectations and partial credibility contribute to a stronger liquidity effect by slowing down the adjustment of agents' inflation forecasts. Unlike our model, however, dynamic general equilibrium models are typically silent regarding the implications of monetary policy for the long-term nominal interest rate. ${ }^{11}$

Our numerical simulations show that disinflation proceeds most rapidly and least painfully under rational expectations/full credibility. As we deviate from this baseline case with either adaptive expectations or partial credibility, the disinflation episode becomes longer and the resulting sacrifice ratio (defined in terms of real output) becomes larger. We find that full credibility can shorten the episode by 7 to 9 quarters and can reduce the sacrifice ratio by a factor of one-fourth to one-third. The simulations also show that incremental reductions in the sacrifice ratio are largest at the low end of the credibility range. Keeping in mind that our model abstracts from any economic benefits of lower inflation, this result suggests that a central bank may face diminishing returns in its efforts to enhance credibility (for example, through a legislative mandate to pursue price stability).

Finally, to provide an estimate of the welfare cost of disinflation, we translate the cumulative loss in real output into a measure based on utility maximization principles. Our measure is the constant percentage increase in per-period consumption that makes a representative household indifferent to experiencing the economic fluctuations attributable to the disinflationary policy. Although full credibility can significantly reduce the sacrifice ratio, its effect on the welfare cost of the disinflation is quite small- less than $0.1 \%$ of per period consumption for all specifications of the model. This outcome is not surprising given the well-known result of Lucas (1987), who shows that the welfare cost of fluctuations attributable to all sources is very small.

The model's predictions regarding the sacrifice ratio are consistent with two cross-country empirical studies. Ball (1994) finds that lower sacrifice ratios are associated with more rapid

\footnotetext{
${ }^{11}$ An exception is the model of Evans and Marshall (1998).
} 
disinflations while Boschen and Weise (1996) find that lower sacrifice ratios are associated with a higher index of economic and political factors that influence prior credibility. Our findings also complement a wide variety of quantitative research on the potential benefits of central bank credibility during a disinflation. Examples include Meyer and Webster (1982), Fischer (1986), Ball (1995), Ireland (1995), Ruge-Murcia (1995), Blake and Westaway (1996), King (1996), Bomfim et al. (1997), Bomfim and Rudebusch (1997), and Andolfatto and Gomme (1997).

The remainder of the paper is organized as follows. Section 2 describes the model and the different specifications of expectations and credibility. Section 3 presents our parameter estimates and examines their sensitivity to different sample periods. Section 4 presents our quantitative results. Section 5 concludes. An appendix provides the details regarding the derivation of our welfare cost measure.

\section{The Model}

The model is a version of the one developed by Fuhrer and Moore (1995a,b). This framework has the advantage of being able to reproduce the pattern of dynamic correlations exhibited by an unconstrained vector autoregression system involving U.S. inflation, short-term nominal interest rates, and deviations of real output from trend. In the model, agents' expectations explicitly take into account the nature of the monetary policy regime, as summarized by the parameters of the central bank reaction function. However, since the other parts of the economy are specified as reduced-form equations, the model is susceptible to Lucas's (1976) econometric policy critique. Our estimation procedure attempts to gauge the quantitative importance of the Lucas critique for our results by examining the stability of the model's reduced form parameters across different sample periods. ${ }^{12}$ The equations that describe the model are as follows:

Aggregate Demand / I-S curve:

$$
\tilde{y}_{t}=a_{1} \tilde{y}_{t-1}+a_{2} \tilde{y}_{t-2}+a_{\rho}\left(\rho_{t-1}-\bar{\rho}\right)+\varepsilon_{y t},
$$

where $\tilde{y}_{t}$ is the so-called "output gap" defined as the deviation of log per-capita real output from trend and $\rho_{t-1}$ is the lagged value of the ex ante long-term real interest rate. The error term $\varepsilon_{y t} \sim N\left(0, \sigma_{\varepsilon y}^{2}\right)$ captures random fluctuations in aggregate demand. We assume that the steady-state value of $\tilde{y}_{t}$ is zero, which implies that $\bar{\rho}$ is the steady-state real interest rate.

\footnotetext{
${ }^{12}$ Fuhrer (1997a) extends the basic Fuhrer-Moore model to include a more rigorous set of microfoundations based on consumer and firm optimization. He concludes that these additional restrictions "imply dynamic behavior that is grossly inconsistent with the data."
} 
Wage Contracting Specification / Short-Run Phillips Curve:

$$
\pi_{t}=\frac{1}{2}\left(\pi_{t-1}+E_{t} \pi_{t+1}\right)+\frac{\gamma}{2}\left(\tilde{y}_{t}+\tilde{y}_{t-1}\right)+\varepsilon_{\pi t},
$$

where $\pi_{t}$ is the inflation rate defined as the log-difference of the price level, $E_{t}$ is the expectation operator conditional on information available at time $t$, and $\varepsilon_{\pi t} \sim N\left(0, \sigma_{\varepsilon \pi}^{2}\right)$ is an error term. Equation (2) can be derived from a two-period model of staggered nominal wage contracts, where the real value of the contract price negotiated at time $t$ is a simple average of the real contract price negotiated at $t-1$ and the real contract price that agents expect to negotiate at $t+1$, adjusted for levels of aggregate demand. The forward-looking nature of wage contracts creates an environment where current inflation depends on expected inflation. The error term represents a stochastic disturbance that affects labor supply decisions. ${ }^{13}$ The steady-state version of (2) implies that there is no long-run trade-off between inflation and real output.

The "sticky-inflation" environment implied by (2) was originally proposed by Buiter and Jewitt (1981). This differs from the "sticky-price" contracting model of Taylor (1980) in which the nominal value of the contract price at time $t$ depends on the nominal contract prices negotiated in the recent past and those expected to prevail in the future. A two-period version of Taylor's model yields

$$
\pi_{t}=E_{t} \pi_{t+1}+\gamma\left(\tilde{y}_{t}+\tilde{y}_{t-1}\right)+\varepsilon_{\pi t}
$$

which recovers a New-Keynesian style Phillips curve. ${ }^{14}$ Fuhrer and Moore (1995a) show that the presence of $\pi_{t-1}$ in the contracting equation improves the model's ability to match the positive correlation between inflation and the real output gap in U.S. data. This correlation and its counterpart - the negative correlation between inflation and unemployment-provide evidence of a short-term Phillips curve trade-off for the postwar U.S. economy. ${ }^{15}$

Equation (2) represents a simplification of the original Fuhrer-Moore contracting specification which involves four-period staggered wage contracts and allows expectations of future output gaps to influence current inflation. Our setup, which is chosen for convenience, weakens the forward-looking component of wage setting behavior. This has implications for the model's disinflation dynamics. We will return to this point later (in Section 4.1) when we discuss the quantitative results.

\footnotetext{
${ }^{13}$ We do not explicitly link the supply shock $\varepsilon_{\pi t}$ to the real price of oil. Fuhrer and Moore (1995a, footnote 15) report that oil prices are uncorrelated with the residuals of their contracting equation, suggesting that their omission does not affect the model's performance. See Bernanke, Gertler, and Watson (1997) for an empirical study of the potential links between oil prices and monetary policy.

${ }^{14}$ A Neoclassical style Phillips curve would take the form $\pi_{t}=E_{t-1} \pi_{t}+\gamma\left(\tilde{y}_{t}+\tilde{y}_{t-1}\right)+\varepsilon_{\pi t}$. See Kiley (1998) for a comparison of the two setups.

${ }^{15}$ King and Watson (1994) document the robust negative correlation between inflation and unemployment at business cycle frequencies.
} 


\section{Central Bank Reaction Function:}

$$
r_{t}=r_{t-1}+\alpha_{\pi}\left(\pi_{t}-\bar{\pi}\right)+\alpha_{y} \tilde{y}_{t}+\varepsilon_{r t},
$$

where $r_{t}$ is the short-term nominal interest rate, $\bar{\pi}$ is the inflation target, and $\varepsilon_{r t} \sim N\left(0, \sigma_{\varepsilon r}^{2}\right)$ is an exogenous stochastic shock that is not directly observed by the public. The policy rule implies that the central bank strives to smooth short-term interest rates, but responds to deviations of inflation from target and to deviations in output from trend. The strength of the interest rate response is governed by the parameters $\alpha_{\pi}$ and $\alpha_{y} \cdot{ }^{16}$ Following the VAR literature, we interpret $\varepsilon_{r t}$ as capturing random, nonsystematic factors that arise from the political process or the interaction of policymakers with different preferences, different target rates of inflation, etc. Alternatively, we could interpret $\varepsilon_{r t}$ as reflecting operational or institutional features that preclude perfect control of $r_{t} .{ }^{17}$ The presence of the unobservable shock is crucial for the credibility analysis because it prevents agents from being able to learn the true value of $\bar{\pi}$ from observations of $r_{t}, r_{t-1}, \pi_{t}$, and $\tilde{y}_{t}$. Equation (3) implies that the steady-state inflation rate is $\bar{\pi}$.

Real Term Structure:

$$
\rho_{t}+D\left(\rho_{t}-E_{t} \rho_{t+1}\right)=r_{t}-E_{t} \pi_{t+1}
$$

where $D$ is the duration of a real consol that is used here to approximate a finite maturity long-term bond. Equation (4) is an arbitrage condition that equates the expected real holdingperiod return on a long-term bond (interest plus capital gains) with the expected real yield on a short-term Treasury security. In steady-state, (4) implies the Fisher relationship: $\bar{r}=\bar{\rho}+\bar{\pi}$. By repeatedly iterating (4) forward and solving the resulting series of equations for $\rho_{t}$, we obtain the following expression:

$$
\rho_{t}=\frac{1}{1+D} E_{t} \sum_{i=0}^{\infty}\left(\frac{D}{1+D}\right)^{i}\left(r_{t+i}-\pi_{t+1+i}\right),
$$

which shows that the ex ante long-term real rate is a weighted average of current and expected future short-term real rates. ${ }^{18}$

\footnotetext{
${ }^{16}$ The policy rule is similar to one proposed by Taylor (1993), which takes the form: $r_{t}=\left(\bar{\rho}+\pi_{t}\right)+$ $\alpha_{\pi}\left(\pi_{t}-\bar{\pi}\right)+\alpha_{y} \tilde{y}_{t}$, where $\bar{\rho}$ is the steady-state real interest rate. The Taylor rule uses $\bar{\rho}=0.02, \alpha_{\pi}=\alpha_{y}=0.5$, and $\bar{\pi}=0.02$. See Taylor (1999) and Judd and Rudebusch (1998) for studies of how policy rules of this type fit U.S. interest rate data.

${ }^{17}$ Cuckierman and Meltzer (1986) develop a model in which the central bank intentionally adopts an imprecise monetary control process in order to obscure its preferences, and thereby exploit a more favorable ouput-inflation trade-off.

${ }^{18}$ In going from (4) to (5) we have applied the law of iterated mathematical expectations.
} 
Nominal Term Structure:

$$
\begin{aligned}
& R_{t}+D\left(R_{t}-E_{t} R_{t+1}\right)=r_{t} \\
& R_{t}=\frac{1}{1+D} E_{t} \sum_{i=0}^{\infty}\left(\frac{D}{1+D}\right)^{i} r_{t+i}
\end{aligned}
$$

where $R_{t}$ is the nominal yield on the long-term bond. The above equations are the nominal counterparts of (4) and (5). In steady-state, equation (6) implies $\bar{R}=\bar{r}$.

Okun's Law:

$$
u_{t}=\left(1-b_{1}\right) \bar{u}+b_{1} u_{t-1}+b_{2} \tilde{y}_{t}+b_{3} \tilde{y}_{t-1}+b_{4} \tilde{y}_{t-2}+\varepsilon_{u t},
$$

where $u_{t}$ is the unemployment rate, $\bar{u}$ is the corresponding steady-state, and $\varepsilon_{u t} \sim N\left(0, \sigma_{\varepsilon u}^{2}\right)$ is an error term. ${ }^{19}$

\subsection{Expectations}

To close the model, we must specify how expectations are formed. We consider two possibilities: the standard assumption of rational expectations and an alternative one where agents' forecasts are constructed using a first-order vector autoregression that involves a subset of known variables. This setup can be viewed as a particular form of adaptive (or distributed lag) expectations. Ordinarily, adaptive expectations are difficult to justify because agents are assumed not to learn from systematic prediction errors. Our focus here, however, is on the transition period immediately following a major policy change. As noted by Taylor (1975, 1993) and Friedman (1979), less-than-rational expectations are more plausible during transitions because agents may not have had sufficient time to discover the "true" specification of the policy rule. ${ }^{20}$

In support of the above argument, we note that empirical evidence suggests the presence of some "irrationality" in the formation of expectations during the Volcker era. For example, the term structure forecast errors identified by Blanchard (1984) exhibit a sustained sequence of one sign from 1980:1 to 1984:3. ${ }^{21}$ Lewis (1989) finds evidence that forward markets in foreign exchange systematically underpredicted the strength of the U.S. dollar from 1980 through 1985. She shows that only about one-half of this underprediction can be accounted for by a

\footnotetext{
${ }^{19}$ Since $\bar{u}$ is independent of $\pi_{t}$, it can be interpreted as the "natural rate of unemployment."

${ }^{20}$ This point is closely related to the growing literature that introduces adaptive learning schemes or boundedly rational agents into economic models. For a review, see Sargent (1993). Lovell (1986) surveys the empirical evidence in support of less-than-rational expectations.

${ }^{21}$ More generally, Chow (1989) shows that a term structure model with adaptive expectations outperforms one with rational expectations in accounting for monthly interest rate movements from 1959:2 to 1983:10.
} 
model in which agents are rationally learning about a key parameter in the money demand equation. Hafer (1983) finds evidence of bias and inefficiency in survey-based measures of weekly money supply forecasts during the 1979-1982 period, in contrast to the unbiased and efficient nature of these forecasts prior to October 1979.

We also note that our use of a reduced-form model tends to blur the distinction between rational and adaptive expectations. Roberts (1997) points out that the Fuhrer-Moore contracting model with rational expectations can be interpreted as an alternative version of Taylor's contracting model in which expectations are "not-quite rational," but instead are determined by an average of adaptive and rational expectations. To see this, note that equations (2) and $\left(2^{\prime}\right)$ are observationally equivalent if one replaces the expectation term in $\left(2^{\prime}\right)$ with an average of $\pi_{t-1}$ and $E_{t} \pi_{t+1}$.

Our specification of adaptive expectations takes the form:

$$
\left[\begin{array}{c}
E_{t} \tilde{y}_{t+1} \\
E_{t} \pi_{t+1} \\
E_{t} r_{t+1} \\
E_{t} R_{t+1}
\end{array}\right]=\mathbf{A}\left[\begin{array}{c}
\tilde{y}_{t} \\
\pi_{t} \\
r_{t} \\
R_{t}
\end{array}\right]+\mathbf{c},
$$

where $\mathbf{A}$ is a $4 \times 4$ matrix of coefficients estimated by a first-order vector autoregression on U.S. data and $\mathbf{c}$ is a $4 \times 1$ matrix of constants defined so that (9) is consistent with the model steady state. The forecast of the ex ante real rate under adaptive expectations is constructed using observable variables as follows

$$
E_{t} \rho_{t+1}=E_{t} R_{t+1}-E_{t} \pi_{t+1}
$$

where $E_{t} R_{t+1}$ and $E_{t} \pi_{t+1}$ are given by (9). This expression implies that agents' forecasts do not distinguish between the ex ante and ex post real rate in period $t+1$.

In the quantitative simulations, we show that forecasts of U.S. inflation constructed using (9) capture a key feature of real-time inflation forecasts recorded in surveys. In particular, the survey-based forecasts tend to systematically underpredict U.S. inflation in the sample period prior to October 1979, but systematically overpredict it thereafter. ${ }^{22}$

\subsection{Credibility}

In modeling the role of credibility during the Volcker disinflation, we abstract from the Fed's adoption of a new operating procedure for targeting nonborrowed reserves from October 1979 to October 1982. Studies by Cook (1989) and Goodfriend (1993) indicate that the majority

\footnotetext{
${ }^{22}$ See Evans and Wachtel (1993) for further documentation of this fact and a model of inflation regime switching that helps account for it.
} 
of federal funds rate movements during this period were the result of deliberate, judgemental policy actions by the Fed, and not automatic responses to deviations of the money stock from its short-run target. ${ }^{23}$ It has been suggested that the Fed's emphasis on monetary aggregates during this period was simply a device that allowed it to disclaim responsibility for pushing up short-term nominal interest rates to levels that would otherwise have been politically infeasible. Based on the above reasoning, we interpret the Fed's statement on October 6, 1979 as an announcement of a reduction in the inflation target. ${ }^{24}$

The experiment we consider is one in which the central bank announces a program to reduce the prevailing rate of inflation and then immediately embarks on such a path by lowering the value of $\bar{\pi}$ in (3). This action constitutes a regime shift that is consistent with the empirical evidence of a statistical break in U.S. inflation occurring around October $1979 .{ }^{25}$ It is important to note that we have simply posited the central bank's decision to lower $\bar{\pi}$, since our model abstracts from any economic benefits of lower inflation. Moreover, we do not attempt to explain how the central bank allowed inflation to become too high in the first place. ${ }^{26}$

We define credibility as the public's subjective probabilistic belief that the announced change in $\bar{\pi}$ has in fact occurred. To formalize this idea, we endow agents with the knowledge of two possible inflation targets $\bar{\pi} \in\left\{\bar{\pi}_{H}, \bar{\pi}_{L}\right\}, \bar{\pi}_{H}>\bar{\pi}_{L}$, and the corresponding equilibrium distributions of $\pi_{t}$ that arise under each. In a stationary equilibrium, the linearity of the model, together with the assumptions that $\varepsilon_{y t}, \varepsilon_{\pi t}$, and $\varepsilon_{r t}$ are i.i.d. normal implies

$$
\pi_{t} \sim N\left(\bar{\pi}, \sigma_{\pi}^{2}\right)
$$

where the mean of the inflation distribution is the steady-state and the variance $\sigma_{\pi}^{2}$ depends on the variances of the stochastic shocks. We assume that the economy is initially in a stationary equilibrium with $\pi_{t} \sim N\left(\bar{\pi}_{H}, \sigma_{\pi}^{2}\right)$. At $t=t^{*}$ the central bank reduces the inflation target to $\bar{\pi}_{L}$ and announces this action to the public. By defining $\hat{\varepsilon}_{r t} \equiv \varepsilon_{r t}+\alpha_{\pi}\left(\bar{\pi}_{H}-\bar{\pi}_{L}\right)$, we can interpret the central bank's action as being part of an exogenous policy shock $\hat{\varepsilon}_{r t}$ for $t \geq t^{*}$. The unobservable component $\varepsilon_{r t}$ prevents the public from being able to verify the central bank's announcement from observations of $r_{t}, r_{t-1}, \pi_{t}$, and $\tilde{y}_{t}$. Hence, the public's belief regarding $\bar{\pi}$ is used to form expectations while the true value of $\bar{\pi}$ is used in (3) to compute the periodby-period values of $r_{t}$. Learning takes place (as described below) and the economy eventually

\footnotetext{
${ }^{23}$ It is straightforward to append a money demand equation that determines how much money the central bank must supply in order to achieve the value of $r_{t}$ given by (3). This would have no effect on the model's dynamics.

${ }^{24}$ Evidence that the public perceived the statement in this way can be found in published newspaper reports of the time. See, for example, "Fed Takes Strong Steps to Restrain Inflation, Shifts Monetary Tactic," The Wall Street Journal, October 8, 1979, p. 1.

${ }^{25}$ See, for example, Walsh (1988).

${ }^{26}$ See Sargent (1999) for a model that seeks to endogenize the rise and fall of U.S. inflation.
} 
converges to a new stationary equilibrium with $\pi_{t} \sim N\left(\bar{\pi}_{L}, \sigma_{\pi}^{2}\right)$. The variance of the long-run inflation distribution is not affected by the change in the inflation target because $\bar{\pi}$ enters additively in (3).

We consider two specifications of credibility, labeled "full" and "partial." Full credibility implies that agents assign the probability $p_{t}=1$ to the event $\bar{\pi}=\bar{\pi}_{L}$ for all $t \geq t^{*}$. Under partial credibility, agents assign a "prior" probability to the event $\bar{\pi}=\bar{\pi}_{L}$ at the time of the announcement. This prior is a free parameter that is influenced by the central bank's past track record in maintaining control over inflation. Agents compute a sequence of posterior probabilities $\left\{p_{t}\right\}_{t=t^{*}}^{\infty}$ by updating their prior in a (quasi) Bayesian way on the basis of observed realizations of the inflation rate and knowledge of the two long-run distributions of inflation centered at $\bar{\pi}_{H}$ and $\bar{\pi}_{L}$. The degree of central bank credibility is indexed by $p_{t}$. We make the simplifying assumption that agents do not take into account the evolving nature of the inflation distribution during the transition to the new stationary equilibrium. Furthermore, we follow Meyer and Webster (1982), Lewis (1989), Baxter (1989), and Fuhrer and Hooker (1993), in assuming that the central bank's policy action is a once-and-for-all change. Thus, agents do not consider the possibility of any future regime shifts when forming their expectations. ${ }^{27}$

The public's beliefs regarding the true value of $\bar{\pi}$ for $t \geq t^{*}$ evolve according to a version of Bayes' rule:

$$
p_{t}=\frac{p_{t-1} \operatorname{Pr}\left(\pi_{t} \leq \pi_{t-1} \mid \bar{\pi}=\bar{\pi}_{L}\right)}{p_{t-1} \operatorname{Pr}\left(\pi_{t} \leq \pi_{t-1} \mid \bar{\pi}=\bar{\pi}_{L}\right)+\left(1-p_{t-1}\right) \operatorname{Pr}\left(\pi_{t} \leq \pi_{t-1} \mid \bar{\pi}_{=} \bar{\pi}_{H}\right)},
$$

with $p_{t^{*}-1}$ given. The posterior probability $p_{t} \equiv \operatorname{Pr}\left(\bar{\pi}=\bar{\pi}_{L} \mid \pi_{t} \leq \pi_{t-1}\right)$ is computed by combining the prior probability $p_{t-1} \equiv \operatorname{Pr}\left(\bar{\pi}=\bar{\pi}_{L}\right)$ with in-sample information. Specifically, the prior is weighted by $\operatorname{Pr}\left(\pi_{t} \leq \pi_{t-1} \mid \bar{\pi}=\bar{\pi}_{L}\right)$, which represents the probability that inflation in period $t$ will be lower than inflation observed in period $t-1$, conditional on the value of the inflation target. The relevant probability weights in (12) are given by

$$
\begin{aligned}
\operatorname{Pr}\left(\pi_{t} \leq \pi_{t-1} \mid \bar{\pi}=\bar{\pi}_{L}\right) & =\int_{-\infty}^{\pi_{t-1}} f_{L}(z) d z, \\
\operatorname{Pr}\left(\pi_{t} \leq \pi_{t-1} \mid \bar{\pi}=\bar{\pi}_{H}\right) & =\int_{-\infty}^{\pi_{t-1}} f_{H}(z) d z,
\end{aligned}
$$

where $f_{L}(z)$ and $f_{H}(z)$ are the normal density functions that describe the stationary inflation distributions centered at $\bar{\pi}_{L}$ and $\bar{\pi}_{H}$, respectively.

Three features of the above specification warrant comment. First, the integrals in (13) and (14) are computed using the observation of $\pi_{t-1}$, not $\pi_{t}$. This is done to preserve the model's

\footnotetext{
${ }^{27}$ See Gagnon (1997) for a univariate model of inflation that relaxes both of the foregoing assumptions.
} 
linearity in $\pi_{t}$ by avoiding simultaneity in the determination of actual and expected inflation. In particular, since $p_{t}$ is used to construct $E_{t} \pi_{t+1}$ (as described below), the specification $p_{t}=p\left(\pi_{t}\right)$ would imply that $(2)$ is nonlinear in the current period inflation rate. Maintaining linearity in $\pi_{t}$ is desirable because it greatly simplifies the model solution procedure. ${ }^{28}$

Second, (13) and (14) imply that probability inferences are made using observations of a single economic variable (inflation), and that the relevant data sample includes only the most recent inflation rate, not the whole history of inflation rates $\left\{\pi_{t-i}\right\}_{i=1}^{t-t^{*}}$ observed since the announcement. ${ }^{29}$ While our setup maintains tractability, it introduces some non-rationality into agents' forecasts to the extent that they ignore the potentially valuable information contained in the whole history of joint observations on inflation, interest rates, and the real output gap. ${ }^{30}$

Third, equation (12) differs from the standard classification formula for computing the conditional probability that a given observation comes from one of two populations with known densities. ${ }^{31}$ In our model, the standard formula would take the form

$$
p_{t}=\frac{p_{t-1} f_{L}\left(\pi_{t-1}\right)}{p_{t-1} f_{L}\left(\pi_{t-1}\right)+\left(1-p_{t-1}\right) f_{H}\left(\pi_{t-1}\right)},
$$

which says that $p_{t}$ depends on the relative heights of the two density functions evaluated at $\pi_{t-1}$. In contrast, equation (12) says that $p_{t}$ depends on the relative areas of the two density functions to the left of $\pi_{t-1}$. In the numerical simulations, we find that (12) quickens the pace of learning in comparison to $\left(12^{\prime}\right)$ and thus leads to more a realistic transition time between steady states. This occurs because (12) introduces an implicit bias into agents' inferences such that $p_{t}$ is higher than that implied by $\left(12^{\prime}\right)$, for any given value of $p_{t-1}$. For the parameter values we consider, both (12) and $\left(12^{\prime}\right)$ exhibit the desirable property that the credibility index $p_{t}$ declines monotonically as inflation rises, for any given $p_{t-1}{ }^{32}$

After computing the posterior probability, agents' expectations (either rational or adaptive) are formed as a weighted average of the forecasts that would prevail under each of the two

\footnotetext{
${ }^{28}$ The literature on learning in self-referential models typically assumes that only lagged values of the endogenous variables are used in the learning rule. See, for example, Marcet and Sargent (1989, equation 4a) and Marcet and Nicolini (1997, equation 12).

${ }^{29}$ The history of inflation does influence credibility, however, because it is incorporated into agents' prior beliefs, which are summarized by $p_{t-1}$ in (12).

${ }^{30}$ See Ruge-Murcia (1995) for a model where credibility is inferred using joint observations of fiscal and monetary variables.

${ }^{31}$ See Anderson (1958), Chapter 6.

${ }^{32}$ This property obtains because the ratios $\frac{\int_{-\infty}^{\pi} f_{L}(z) d z,}{\int_{-\infty}^{\pi} f_{H}(z) d z}$, and $\frac{f_{L}(\pi)}{f_{H}(\pi)}$ are both monotonically decreasing in $\pi$ for the inflation rates encountered during the simulations.
} 
possible inflation targets:

$$
\begin{aligned}
E_{t} \pi_{t+1} & =p_{t} E_{t}\left[\pi_{t+1} \mid \bar{\pi}=\bar{\pi}_{L}\right]+\left(1-p_{t}\right) E_{t}\left[\pi_{t+1} \mid \bar{\pi}=\bar{\pi}_{H}\right], \\
E_{t} \rho_{t+1} & =p_{t} E_{t}\left[\rho_{t+1} \mid \bar{\pi}=\bar{\pi}_{L}\right]+\left(1-p_{t}\right) E_{t}\left[\rho_{t+1} \mid \bar{\pi}=\bar{\pi}_{H}\right], \\
E_{t} R_{t+1} & =p_{t} E_{t}\left[R_{t+1} \mid \bar{\pi}=\bar{\pi}_{L}\right]+\left(1-p_{t}\right) E_{t}\left[R_{t+1} \mid \bar{\pi}=\bar{\pi}_{H}\right] .
\end{aligned}
$$

where $p_{t}$ is given by (12). Since $p_{t}$ is a function of past inflation, the rational expectations version of the model will now exhibit some of the backward-looking characteristics of traditional adaptive expectations. ${ }^{33}$

Our specification of credibility in the form of beliefs about two possible and known values of $\bar{\pi}$ is obviously a simplification of the complicated learning problem faced by real-world agents following a policy regime change. To achieve a more realistic setup, one could possibly assume that agents employ a Kalman filter or a least squares regression algorithm to continually update their estimate of $\bar{\pi}$ (or the matrices $\mathbf{A}$ and $\mathbf{c}$ in equation (9)) as the economy evolves over time. ${ }^{34}$ Our simple specification will serve to illustrate some basic points that we believe are likely to carry over to more elaborate learning schemes.

\section{Estimation and Calibration}

For the purpose of estimating parameters, we adopt a baseline model specification that incorporates rational expectations and full credibility. The resulting parameter set is then used for all model specifications to maintain comparability in the simulations. The data used in the estimation procedure are summarized in Table 1.

Table 1: Quarterly Data, 1965:1 to 1996:4

\begin{tabular}{cl}
\hline \hline Variable & \multicolumn{1}{c}{ Definition } \\
\hline$\tilde{y}_{t}$ & Deviation of log per capita real GDP (fixed-weight) from its linear trend. \\
$\pi_{t}$ & Log-difference of GDP price deflator (fixed-weight). \\
$r_{t}$ & Yield on 3 month Treasury bill. \\
$R_{t}$ & Yield on 10 year constant-maturity Treasury bond. \\
$u_{t}$ & Nonfarm civilian unemployment rate. \\
\hline \hline
\end{tabular}

\footnotetext{
${ }^{33}$ A similar effect obtains in the models of Fisher (1986), Ireland (1995), Blake and Westaway (1996), King (1996), Bomfim, et al. (1997), and Bomfim and Rudebusch (1997). In these models, credibility is determined by a backward-looking, linear updating rule. In contrast, Ball (1995) models credibility using a purely timedependent probability measure.

${ }^{34}$ This type of approach to learning is taken by Friedman (1979), Cripps (1991), Fuhrer and Hooker (1993), Sargent (1999), Marcet and Nicolini (1997), and Tetlow and von zur Muehlen (1999), among others.
} 
The model's reduced-form parameters are assumed to be "structural" in the sense that they are invariant to changes in the monetary policy reaction function (3). We attempt to gauge the reasonableness of this assumption by examining the sensitivity of the parameter estimates to different sample periods. Following Fuhrer (1996), we do not estimate the duration parameter but instead calibrate it to the value $D=28$. This coincides with the sample average duration (in quarters) of a 10 year constant-maturity Treasury bond. Equations (1)-(4) form a simultaneous system that we estimate using full-information maximum likelihood. ${ }^{35}$ The estimation results are summarized in Table 2.

Table 2: Maximum Likelihood Parameter Estimates

\begin{tabular}{c|cc|rc|rc}
\hline \hline & \multicolumn{2}{c}{$1965: 1$ to 1996:4 } & \multicolumn{2}{c}{$1965: 1$ to 1979:4 } & \multicolumn{2}{c}{$1980: 1$ to 1996:4 } \\
Parameter & Estimate & \multicolumn{1}{c}{ Std. Error } & Estimate & \multicolumn{1}{c}{ Std. Error } & Estimate & Std. Error \\
\hline$a_{1}$ & 1.23 & 0.09 & 0.94 & 4.97 & 1.24 & 0.10 \\
$a_{2}$ & -0.26 & 0.08 & 0.10 & 4.62 & -0.31 & 0.09 \\
$a_{\rho}$ & -0.20 & 0.12 & -0.57 & 2.17 & -0.05 & 0.05 \\
$\bar{\rho}$ & 0.02 & 0.01 & 0.02 & 0.36 & 0.00 & 0.04 \\
$\gamma$ & 0.01 & 0.01 & 0.04 & 0.47 & 0.01 & 0.01 \\
$\alpha_{\pi}$ & 0.06 & 0.03 & 0.07 & 1.04 & 0.10 & 0.05 \\
$\alpha_{y}$ & 0.08 & 0.03 & 0.07 & 1.05 & 0.05 & 0.06 \\
$\bar{\pi}$ & 0.05 & 0.01 & 0.04 & 0.45 & 0.05 & 0.01 \\
\hline \hline
\end{tabular}

With the exception of $a_{\rho}$ and $\gamma$, the parameter estimates from the full sample (1965:1 to 1996:4) are all statistically significant. These results are very much in line with those obtained by Fuhrer and Moore (1995b, Table 4), despite small differences in our model specification and data. Estimates from the first subsample (1965:1 to 1979:4) are highly imprecise, most likely due to the strong upward trends in U.S. inflation and nominal interest rates over this period. Estimates from the second subsample (1980:1 to 1996:4) are much closer to the full-sample results. A comparison of the subsample estimates of $\alpha_{\pi}$ and $\alpha_{y}$ suggests that the Fed placed more emphasis on targeting inflation and less emphasis on stabilizing output in the period after 1980. Evidence of subsample instability seems to be concentrated mostly in the I-S curve parameters $a_{1}, a_{2}$, and $a_{\rho}$. Notice, however, that all subsample point estimates lie within one standard error of each other. We interpret these results to be reasonably supportive of the hypothesis that the reduced-form parameters $a_{1}, a_{2}, a_{\rho}, \bar{\rho}$, and $\gamma$ do not vary across monetary policy regimes.

For the simulations, we require values for $\bar{\pi}_{H}$ and $\bar{\pi}_{L}$. Given the imprecise nature of the first subsample estimate of $\bar{\pi}$, we choose $\bar{\pi}_{H}=0.06$ to coincide with the sample mean from 1965:1 to 1979:4. Thus, we assume that the U.S. inflation rate prior to October 1979

\footnotetext{
${ }^{35}$ We use the Matlab programs developed by Fuhrer and Moore (1995b), as modified to reflect the differences in our model specification and data.
} 
can be characterized by a stationary distribution centered at $6 \%$. While this assumption is undoubtedly false, it will serve to illustrate the effects of partial credibility on the disinflation episode. Since $\bar{\pi}_{L}$ is intended to represent the new steady-state after the disinflation has been completed, we choose $\bar{\pi}_{L}=0.03$ to coincide with the sample mean from 1985:1 to 1996:4. In computing this average, we omit the period of rapidly falling inflation from 1980:1 to 1984:4 because this can be interpreted as the transition to the new steady state. ${ }^{36}$ For the other model parameters, we adopt the full-sample estimates in Table 2.

Our disinflation simulations abstract from stochastic shocks because these have the potential to obscure differences between the dynamic propagation mechanisms of the various model specifications. ${ }^{37}$ We assume, however, that agents make decisions as if uncertainty were present. This assumption is necessary for a meaningful analysis of credibility because without uncertainty, agents can always learn the true value of $\bar{\pi}$ within two periods. To compute the integrals in (13) and (14), we simply calibrate the standard deviations of the two long-run inflation distributions centered at $\bar{\pi}_{H}$ and $\bar{\pi}_{L}$. For both distributions, we choose $\sigma_{\pi}=0.023$ to coincide with the sample standard deviation from 1965:1 to 1979:4. This reflects our interpretation that the Fed's announcement on October 6, 1979 concerned only a change in the target level of inflation, not a change in the target variability of inflation. ${ }^{38}$ We use the same value of $\sigma_{\pi}$ for all model specifications.

For the steady-state unemployment rate, we choose $\bar{u}=0.06$ to coincide with the average over the full sample. Given $\bar{u}$, we estimate the parameters of Okun's law (8) using ordinary least squares to obtain $b_{1}=0.96, b_{2}=-0.30, b_{3}=0.10$, and $b_{4}=0.18$, which are all statistically significant.

The matrix $\mathbf{A}$ in (9) is estimated by an unrestricted first-order VAR on U.S. data from 1965:1 to 1996:4. The result is

$$
\mathbf{A}=\left[\begin{array}{rrrr}
0.953 & 0.002 & -0.197 & 0.096 \\
0.111 & 0.628 & 0.290 & -0.211 \\
0.093 & 0.073 & 0.839 & 0.055 \\
0.012 & 0.053 & 0.039 & 0.907
\end{array}\right]
$$

\footnotetext{
${ }^{36}$ The values $\bar{\pi}_{H}=0.06$ and $\bar{\pi}_{L}=0.03$ are very close to those used by Fuhrer (1996, figure IIb) to help reconcile the pure expectations theory of the term structure with U.S. nominal interest rate data.

${ }^{37}$ Since equation (12) is nonlinear, the addition of stochastic shocks would affect the mean length and speed of the disinflation under partial credibility. See Orphanides, et al. (1997) and Bomfim and Rudebusch (1997) for studies that investigate disinflation dynamics in stochastic models with a nonlinear monetary policy rule.

${ }^{38}$ We relax this assumption in Huh and Lansing (1998) by allowing the reaction function parameters $\alpha_{\pi}$ and $\alpha_{y}$ to shift in conjunction with the Fed's announcement.
} 
Given A, we define two versions of the matrix $\mathbf{c}$ so that (9) will be consistent with the two steady states associated with $\bar{\pi}_{H}$ and $\bar{\pi}_{L}$, respectively. This procedure yields

$$
\mathbf{c}=\left\{\begin{array}{l}
{\left[\begin{array}{l}
0.008 \\
0.016 \\
0.004 \\
0.001
\end{array}\right] \text { when } \bar{\pi}=\bar{\pi}_{H}=0.06} \\
{\left[\begin{array}{l}
0.005 \\
0.007 \\
0.003 \\
0.001
\end{array}\right] \text { when } \bar{\pi}=\bar{\pi}_{L}=0.03}
\end{array}\right.
$$

Our solution procedure can be briefly summarized as follows. Given a set of parameters and an assumption regarding the way that expectations are formed (rational or adaptive), we solve the full-information version of the model for each of the two cases: $\bar{\pi}=\bar{\pi}_{H}$ and $\bar{\pi}=\bar{\pi}_{L}$. In each case, the solution consists of a set of time-invariant linear decision rules for $\pi_{t}, \rho_{t}$, and $R_{t}$, defined in terms of the "state" vector $s_{t}=\left\{\tilde{y}_{t-1}, \tilde{y}_{t-2}, \pi_{t-1}, \rho_{t-1}, r_{t-1}\right\}$. The decision rules for $\tilde{y}_{t}$ and $r_{t}$ are simply given by (1) and (3), respectively. For each value of $\bar{\pi} \in\left\{\bar{\pi}_{H}, \bar{\pi}_{L}\right\}$, we construct linear expressions for the conditional expectations $E_{t}\left[\pi_{t+1} \mid \bar{\pi}\right], E_{t}\left[\rho_{t+1} \mid \bar{\pi}\right]$, and $E_{t}\left[R_{t+1} \mid \bar{\pi}\right]$. Under rational expectations, these expressions are constructed using the decision rules, whereas under adaptive expectations, the expressions are constructed using (9) and (10). Next, we form the unconditional expectations $E_{t} \pi_{t+1}, E_{t} \rho_{t+1}$, and $E_{t} R_{t+1}$ using the current value of $p_{t}$ (which does not depend on $\pi_{t}$ ) and (15)-(17). Finally, the unconditional expectations are substituted into (2), (4), and (6) which, together with (1) and (3), form a system of linear equations in the variables $\tilde{y}_{t}, \pi_{t}, \rho_{t}, r_{t}$, and $R_{t}$.

Under full credibility, it is straightforward to show that the model possesses a unique, stable equilibrium for the parameters values we employ. ${ }^{39}$ Under partial credibility, agents use observations of an endogenous variable (inflation) to form expectations that are crucial for determining the period-by-period values of that same variable. The presence of this dynamic feedback effect between the trajectory of inflation and the inputs to the learning process can create an environment where learning goes astray. In particular, there is no way to guarantee that the model will converge to a new steady state with $\bar{\pi}=\bar{\pi}_{L} \cdot{ }^{40}$ We find that convergence is always achieved in the numerical simulations, however.

\footnotetext{
${ }^{39}$ The steady states associated with $\bar{\pi}_{H}$ and $\bar{\pi}_{L}$ both exhibit the well-known saddle-point property.

${ }^{40}$ In contrast, Taylor (1975), Meyer and Webster (1982), Baxter (1989), and Andolfatto and Gomme (1997), among others, consider Bayesian learning models in which agents' expectations do not affect the evolution of the variables they form expectations about. Hence, convergence follows from standard results on the asymptotic properties of estimators.
} 


\section{Quantitative Results}

\subsection{Deterministic Disinflation Simulations}

Figures 1 through 6 trace out the deterministic disinflation paths for economic variables under the four different specifications of the model. For the specifications with partial credibility (denoted by the symbol $p<1$ ), we set the initial prior to $0.5 \%$. This reflects our view, noted earlier in the introduction, that the Federal Reserve's credibility was very low at the start of the Volcker era. ${ }^{41}$ Later, in our sensitivity analysis, we will explore how the level of the initial prior affects various aspects of the disinflation episode.

The evolution of credibility is shown in Figure 1. With full credibility, $p_{t}$ jumps immediately to $100 \%$ on the strength of the central bank's announcement at $t^{*}=0$. With partial credibility, $p_{t}$ increases over time as agents observe that $\pi_{t}$ is falling (see Figure 2). This feature of the model is consistent with the findings of Hardouvelis and Barnhart (1989) who show that an empirical proxy for Fed credibility increased only gradually in the period following October 1979. Moreover, they find that credibility is statistically linked to the rate of inflation. ${ }^{42}$

The value $p_{t}=100 \%$ is effectively reached within about $12-16$ quarters after the announcement. Once this occurs, Bayes rule implies that full credibility will be sustained forever, despite the subsequent increase in $\pi_{t}$ that results from the dynamic overshooting characteristics of the model. Our experiments show that by increasing the standard deviation of the initial inflation distribution relative to that of the final distribution, the economy will take longer to reach $p_{t}=100 \%$. As a result, the overshooting behavior in $\pi_{t}$ can cause credibility to temporarily fall during the disinflation episode. In Huh and Lansing (1998), we show that this feature of the model can generate an "inflation scare," as described by Goodfriend (1993).

Figure 1 shows that credibility accumulates more slowly under adaptive expectations. The intuition for this result follows directly from equation (2). With adaptive expectations, the sluggish behavior of $E_{t} \pi_{t+1}$ delays the response of current inflation $\pi_{t}$ to the policy change. This, in turn, delays the accumulation of credibility, which feeds back to inflation expectations. ${ }^{43}$ This effect is clearly evident in Figure 2 which shows that the specification of adaptive expectations/partial credibility yields the most gradual disinflation. The variables

\footnotetext{
${ }^{41}$ A similar view is put forth by Mankiw (1994) who shows that forecasts made by the Council of Economic Advisers in January 1981 predicted a gradual and moderate decline in the inflation rate, in contrast to the rapid and pronounced disinflation policy that actually occurred under Fed Chairman Volcker.

${ }^{42}$ The Hardouvelis-Barnhart measure of credibility is inversely proportional to the response of commodity prices (such as gold and silver) to unanticipated changes in the M1 money stock.

${ }^{43}$ In the words of Fed Chairman Volcker: "Inflation feeds in part on itself, so part of the job of returning to a more stable and more productive economy must be to break the grip of inflationary expectations." See Volcker (1979), pp. 888-889.
} 
$\tilde{y}_{t}, r_{t}, R_{t}$, and $u_{t}$ also respond more slowly in this case. The following table summarizes the speed of response under the four different specifications of the model.

Table 3: Speed of Response to Change in Inflation Target

\begin{tabular}{lcc}
\hline \hline & Full Credibility & Partial Credibility \\
\hline Rational Expectations & Fast & Intermediate \\
Adaptive Expectations & Intermediate & Slow \\
\hline \hline
\end{tabular}

The model with rational expectations is characterized by more overshooting in $\pi_{t}$, but less overshooting in other variables relative to the model with adaptive expectations. Partial credibility serves to magnify the amplitude of the fluctuations in all variables under both forms of expectations. This highlights a potentially important stabilization property of full credibility: stabilization is aided by the elimination of the backward-looking dynamics associated with the learning process. This result is consistent with the findings of Fuhrer (1997b), who shows that a stronger forward-looking component in the wage contracting equation helps to stabilize models of this type. ${ }^{44}$ Fuhrer's findings also help to explain the pronounced oscillations that we observe even under rational expectations. As noted earlier, our two-period contracting specification weakens the forward-looking component of wage-setting behavior in comparison to the four-period setup in the original Fuhrer-Moore model. ${ }^{45}$

In Figure 4, we see that all specifications predict an initial monetary contraction, as evidenced by an increase in the short-term nominal interest rate $r_{t} \cdot{ }^{46}$ Although not shown, the ex ante real interest rate $\rho_{t}$ also increases. This rise in interest rates is followed by a prolonged decrease in real economic activity (Figure 2). Hence, the model captures the "inverse leading indicator" property of nominal and real interest rates documented by King and Watson (1996).

Figure 4 also shows that the specification with adaptive expectations/partial credibility exhibits the greatest degree of monetary tightening, as measured by the peak level of $r_{t}$. This is due to the form of the reaction function (3) that makes $r_{t}$ an increasing function of the distance $\pi_{t}-\bar{\pi}_{L}$ and the level of the current output gap $\tilde{y}_{t}$. Since both $\pi_{t}$ and $\tilde{y}_{t}$ fall slowly under adaptive expectations/partial credibility, the level of $r_{t}$ implied by (3) is highest under this specification. Moreover, the sluggish adjustment of $E_{t} \pi_{t+1}$ means that a higher level of inflation is built into expectations of future short rates. These two effects combine to raise the level of the current long rate $R_{t}$ in comparison to the other three specifications. Figure 5 shows that only in the case of adaptive expectations/partial credibility is the inertia in agents'

\footnotetext{
${ }^{44}$ For a related discussion, see Taylor (1980, section IV).

${ }^{45}$ The forward-looking component of behavior helps to reduce the modulus of the complex eigenvalues that give rise to damped oscillatory behavior in the model variables.

${ }^{46}$ Since $r_{t}$ rises and $\tilde{y}_{t}$ falls, a traditional Keynesian money demand equation with a predetermined price level would imply a contraction of the nominal money stock.
} 
inflation forecasts sufficient to cause $R_{t}$ to rise in response to the tighter monetary policy. ${ }^{47}$ In contrast, the other three specifications predict a fall in $R_{t}$ as agents more quickly lower their inflation expectations.

\subsection{Comparison with Volcker Disinflation}

Figures 7 through 15 compare the evolution of U.S. macroeconomic variables during the Volcker disinflation with the corresponding variables in the model. The vertical line in the U.S. figures marks the start of the Volcker disinflation in October 1979. Since the model simulations depict a permanent, deterministic transition from one steady state inflation rate to another, we focus our comparison on the trend movements in the U.S. variables. The trend movements are more likely to be dominated by permanent changes, as opposed to transitory stochastic shocks which are absent from the model. ${ }^{48}$

The figures show that the model can reasonably approximate the qualitative features of the Volcker disinflation. Interestingly, the U.S. variables appear to exhibit some low frequency, damped oscillations that resemble the dynamic overshooting characteristics of the model variables. This phenomenon is particularly evident in the U.S. real output gap and the U.S. unemployment rate (Figures 8a and 9a). It should be noted, however, that the 16 year sample period following October 1979 may include some additional monetary policy actions that are not present in the model. For example, Taylor $(1993,1998)$ shows that the time path of the federal funds rate since 1987 is well-described by a policy rule with an inflation target of $2 \%$ (see footnote 16). Romer and Romer (1994) find evidence that the Federal Reserve made a deliberate decision to reduce inflation in December 1988.

The behavior of the nominal term structure is shown in Figures 10 through 12. In U.S. data, short- and long-term rates both initially rise in the period following October 1979. The model specification with adaptive expectations/partial credibility yields the most pronounced rise in the short rate $r_{t}$. This result helps to provide some insight into the findings of Pagan and Robertson (1995) who show that the 1979-82 period is a watershed for empirical work that attempts to identify the so-called "liquidity effect" of a monetary policy shock. In particular, they find that when the 1979-1982 period is omitted from the data, there is little evidence of a statistically significant liquidity effect. Bernanke and Mihov (1998) find that estimates derived from a structural VAR model are "consistent with there being no liquidity effect at all in the post-1982 sample." We argued earlier that 1979-1982 was a time when agents' forecasts would

\footnotetext{
${ }^{47}$ A similar result is obtained by Bomfim et al. (1997, figure 3) using a version of the FRB/US model with VAR-based expectations and learning.

${ }^{48}$ The trends are defined using the Hodrick-Prescott filter with a smoothing parameter equal to 1600 . For details, see Hodrick and Prescott (1997).
} 
be inclined to adjust slowly as they attempted to decipher the implications of the Fed's new operating procedure. Our model predicts that when forecasts adjust slowly due to adaptive expectations or partial credibility, a monetary contraction will lead to a more pronounced rise in $r_{t}$ and a more pronounced fall in $\tilde{y}_{t}$, i.e., a stronger liquidity effect.

Blanchard (1984) and Goodfriend (1993) argue that movements in U.S. long-term bond yields in the period following October 1979 indicate that financial markets did not expect inflation to be lowered rapidly. ${ }^{49}$ This idea is captured by the specification with adaptive expectations/partial credibility. As noted earlier, this setup generates enough inertia in $E_{t} \pi_{t+1}$ to cause $R_{t}$ to initially rise in response to tighter monetary policy. More generally, the specification with adaptive expectations/partial credibility is consistent with empirical evidence summarized in Cook and Hahn (1989) and Evans and Marshall (1998). These researchers find that tighter monetary policy leads to an increase in long-term nominal interest rates, with progressively smaller responses as bond maturity is lengthened. Figure 11b shows that the rise in $R_{t}$ is less pronounced than the rise in $r_{t}$. As a result, the term structure spread plotted in Figure 12b initially narrows.

Figure 13 compares actual U.S. inflation with two different expected inflation series. In Figure 13a, we plot the mean one-year-ahead expectation of the rate of change of prices in general, as recorded by the Survey Research Center at the University of Michigan. In Figure $13 \mathrm{~b}$, we construct a one-quarter-ahead forecast of U.S. inflation using the VAR in (9). ${ }^{50}$ Both of these forecasts exhibit the same general pattern, i.e., they tend to systematically underpredict actual U.S. inflation in the sample period prior to October 1979, but systematically overpredict it thereafter. ${ }^{51}$ Roberts (1997) finds evidence that the Michigan survey expectations do not make econometrically efficient use of available information - implying that these expectations are not perfectly rational. Based on these results, we believe that our version of adaptive expectations in (9) provides a reasonable portrayal of real-time inflation forecasts.

Figure 14 plots the ex post long-term real interest rate, defined as $R_{t}-\pi_{t}$, for both the data and the model. The U.S. ex post real rate exhibits a dramatic upward shift from a value near zero prior to October 1979 to a recent value of 4 to 5\%. Evans and Lewis (1995) argue that a bias in market inflation forecasts (due to uncertainty about future monetary policy regimes) has created a systematic divergence between the ex post and ex ante real interest rates in U.S.

\footnotetext{
${ }^{49}$ The long-term rate in Blanchard's analysis is the yield on Aaa-rated corporate bonds. Goodfriend uses the yield on a 30-year Treasury bond. Our analysis uses the yield on a 10-year Treasury bond. All of these yields exhibit upward movement in the period following October 1979.

${ }^{50}$ In constructing this forecast, we use the following version of the matrix $\mathbf{c}$ that is estimated over the full data sample: $\mathbf{c}=\left[\begin{array}{llll}0.006 & 0.016 & 0.003 & 0.002\end{array}\right]^{T}$.

${ }^{51} \mathrm{~A}$ similar pattern is observed in other survey-based measures of expected inflation. See Evans and Wachtel (1993).
} 
data. This effect cannot be captured by the model due to our assumption of a once-and-for-all shift in $\bar{\pi}$. Hence, the model's ex post real rate eventually returns to its original steady-state value of $2 \%$.

\subsection{Length, Speed, and Cost of Disinflation}

We now turn to the effects of expectations and credibility on other features of the disinflation episode.

\subsubsection{Length}

Figure 15 plots the length of the disinflation episode (in quarters) versus the degree of prior credibility. We follow Ball (1994) in defining length as the number of quarters between the "peak" and "trough" of trend inflation. In all cases, we define $t^{*}=0$ as the location of the inflation peak such that $\pi_{\text {peak }}=\bar{\pi}_{H} \cdot{ }^{52}$ The location of the inflation trough varies across specifications depending on the degree of inflation overshooting. This overshooting behavior implies $\pi_{\text {trough }}<\bar{\pi}_{L}$.

Figure 15 shows that a higher degree of prior credibility leads to a shorter disinflation episode. By measuring the vertical distance covered by each line, we find that full credibility can shorten the episode by 7 to 9 quarters. By comparing the height of the dashed line (adaptive expectations) to that of the solid line (rational expectations), we find that rational expectations can shorten the episode by about 16 quarters.

As a benchmark for comparison, we can compute the length of the Volcker disinflation. The trend level of inflation at the start of the episode in 1979:4 is 8.13\%. The trend bottoms out in 1986:4 at 3.50\%. This implies a length of 28 quarters, which lies about midway between the two lines plotted in Figure 15. ${ }^{53}$

\subsubsection{Speed}

Figure 16 plots the speed of disinflation (in percentage points of inflation per quarter) versus the degree of prior credibility. We again follow Ball (1994) in defining speed as the change in trend inflation from peak to trough divided by the length of the episode. The figure shows that a higher degree of prior credibility leads to a more rapid disinflation episode. The speed under rational expectations is about three times higher than the speed under adaptive expectations.

\footnotetext{
${ }^{52}$ This definition is not strictly valid for the specification with adaptive expectations/partial credibility because $\pi_{t}$ can actually increase for about 7 quarters before starting to decline (see figure 2). Nevertheless, we define $t^{*}=0$ as the starting point of the episode to coincide with timing of the change in the inflation target.

${ }^{53}$ Ball (1994, table 5.1) computes a length of 15 quarters (1980:1 to 1983:4) for the Volcker disinflation. In his analysis, trend inflation is defined using a centered, nine-quarter moving average, as opposed to the Hodrick-Prescott filter trend used here.
} 
In our model, the length and speed of the disinflation are both outside of the central bank's control. This is because the shift from $\bar{\pi}_{H}$ to $\bar{\pi}_{L}$ is imposed as an exogenous, once-and-for-all policy change at $t^{*}=0$. One could imagine an alternative environment where the central bank chooses a disinflation trajectory that maximizes some desired objective. This is the approach taken by Taylor $(1975,1983)$ and Ireland (1995). In such an environment, the length and speed of the episode can be controlled by the central bank.

\subsubsection{Sacrifice Ratio}

Figure 17 plots the so-called sacrifice ratio, defined as the undiscounted, cumulative percentage point loss in output (at an annual rate) divided by the change in inflation. In computing this ratio, we adopt a long-term view of the episode such that all fluctuations in real output attributable to the disinflationary policy are taken into account. The sacrifice ratio is defined as

$$
\text { Sacrifice Ratio }=\frac{-\frac{1}{4} \sum_{t=0}^{2000} \tilde{y}_{t}}{\left(\bar{\pi}_{H}-\bar{\pi}_{L}\right)},
$$

where we multiply by $\frac{1}{4}$ to convert the cumulative output loss to an annual basis. The denominator is the change in inflation that takes place over the course of a very long (2000 period) simulation.

Figure 17 shows that higher credibility leads to lower sacrifice ratios. ${ }^{54}$ We obtain sacrifice ratios of 2.1 to 2.8 under rational expectations and 3.3 to 5.2 under adaptive expectations. ${ }^{55}$ These values are well within the range of estimates obtained by other researchers who have analyzed the Volcker disinflation. ${ }^{56}$ Our results are also consistent with the cross-country empirical studies of Ball (1994) and Boschen and Weise (1996) who find that lower sacrifice ratios are associated with more rapid disinflations (Ball) and a higher index of economic and political factors that influence prior credibility (Boschen and Weise).

The simulations show that incremental reductions in the sacrifice ratio are largest at the low end of the credibility range (0 to 20\%). Keeping in mind that our model abstracts from any economic benefits of lower inflation, this result suggests that a central bank may face diminishing returns in its efforts to enhance credibility. This point is particularly relevant to the debate concerning the potential payoff of legislation designed to increase credibility

\footnotetext{
${ }^{54} \mathrm{~A}$ similar result is obtained by Meyer and Webster (1982, table 5) using a version of the Barro (1976) model with rational expectations and partial credibility.

${ }^{55}$ Fuhrer (1994, table 4) examines the sensitivity of the sacrifice ratio to the reaction function parameters $\alpha_{\pi}$ and $\alpha_{y}$ in a model with rational expectations and full credibility. He finds that sacrifice ratios are largest for parameter combinations involving high $\alpha_{\pi}$ and low $\alpha_{y}$.

${ }^{56}$ Examples include Gordon and King (1982, table 5) who obtain values of 3.0 to 8.4, Fisher (1986, section 7.5) who obtains values of 5 to 6 , Ball (1994, table 5.1) who obtains a value of 1.8, Boschen and Weise (1996, table A.1) who obtain values of 2.1 to 3.3, and Mankiw (1997, p. 355) who obtains a value of 2.8.
} 
by requiring the central bank to pursue some notion of "price stability" as its primary or sole objective. Such an arrangement was adopted in New Zealand in 1989 and has also been proposed in the U.S. Congress. ${ }^{57}$

\subsubsection{Welfare Cost}

Despite its common use, the sacrifice ratio does not tell us everything we would like to know about the cost of disinflation. Ideally, central bankers should be concerned about the welfare consequences of their actions. Although our reduced-form model precludes a rigorous welfare analysis, we attempt to provide a rough estimate of the welfare cost of disinflation by translating the cumulative loss in real output into a measure based on utility maximization principles. Following Lucas (1987), we adopt a compensating variation measure, namely, the constant percentage increase in per-period consumption that makes a representative household indifferent to experiencing the economic fluctuations attributable to the disinflationary policy.

In the appendix, we show that by postulating an economy where an infinitely-lived household maximizes a logarithmic utility function, our welfare cost measure can be written as

$$
\Delta W=100\left\{\exp \left[\left(-\sum_{t=0}^{2000} \beta^{t} \tilde{y}_{t}\right)(1-\beta)\right]-1\right\}
$$

where $\beta$ is the quarterly discount factor. Our calibration procedure (described in the appendix) yields $\beta=0.99878$.

Figure 18 shows that higher credibility leads to lower welfare costs. This figure adheres to the same general pattern as Figure 17 , since both $\Delta W$ and the sacrifice ratio depend on the sequence of output gaps. The main point to recognize is that the magnitude of $\Delta W$ is extremely small-less than $0.1 \%$ of per-period consumption for all specifications of the model. These results are of the same order of magnitude as those obtained by Ireland (1995) and Andolfatto and Gomme (1997), who examine the welfare consequences of disinflationary policies in fully-articulated general equilibrium models. In contrast to our analysis, these authors are able to take into account the benefits associated with reducing the distorting effects of the inflation tax on household decisions. As a result, disinflationary policies are welfare-improving in their models. Nevertheless they find, as we do, that credibility has a very small impact on welfare. ${ }^{58}$

\footnotetext{
${ }^{57}$ See Romer and Romer (1997) for a discussion regarding the merits of legislated rules and other institutional arrangements for the conduct of monetary policy.

${ }^{58}$ This result might change in a model that allows for agent heterogeneity or incomplete markets. For example, İmrohoroğlu (1989) shows that liquidity constraints can magnify the welfare cost of business cycles by a factor of four to five in comparison to a perfect insurance economy.
} 
Table 4 provides a summary of our quantitative results.

Table 4: Length, Speed, and Cost of Disinflation

\begin{tabular}{|c|c|c|c|c|c|c|c|c|}
\hline & \multicolumn{4}{|c|}{ Full Credibility } & \multicolumn{4}{|c|}{$\begin{array}{c}\text { Partial Credibility } \\
\text { (prior }=0.5 \%)\end{array}$} \\
\hline & $\begin{array}{l}\text { Length } \\
(q t r s)\end{array}$ & $\begin{array}{l}\text { Speed } \\
(\% / q t r)\end{array}$ & $\begin{array}{c}\text { Sacrifice } \\
\text { Ratio }\end{array}$ & $\begin{array}{l}\Delta W \\
(\%)\end{array}$ & $\begin{array}{l}\text { Length } \\
\text { (qtrs) }\end{array}$ & $\begin{array}{c}\text { Speed } \\
(\% / q t r)\end{array}$ & $\begin{array}{c}\text { Sacrifice } \\
\text { Ratio }\end{array}$ & $\begin{array}{l}\Delta W \\
(\%)\end{array}$ \\
\hline $\begin{array}{c}\text { Rational } \\
\text { Expectations }\end{array}$ & 17 & 0.32 & 2.08 & 0.030 & 23 & 0.27 & 2.62 & 0.038 \\
\hline $\begin{array}{c}\text { Adaptive } \\
\text { Expectations }\end{array}$ & 33 & 0.12 & 3.30 & 0.048 & 40 & 0.11 & 4.74 & 0.069 \\
\hline \multicolumn{9}{|c|}{$\begin{array}{l}\text { Length }=\# \text { quarters between } \pi_{\text {peak }} \text { and } \pi_{\text {trough }} . \quad \text { Speed }=\frac{100\left(\pi_{\text {peak }}-\pi_{\text {trough }}\right)}{\text { Length }} . \\
\text { Sacrifice Ratio }=\frac{-\frac{1}{4} \sum_{t=0}^{2000} \tilde{y}_{t}}{\left(\bar{\pi}_{H}-\bar{\pi}_{L}\right)} . \\
\Delta W=100\left\{\exp \left[\left(-\sum_{t=0}^{2000} \beta^{t} \hat{y}\right.\right.\right.\end{array}$} \\
\hline
\end{tabular}

\section{Conclusion}

This paper developed a simple, quantitative model of the U.S. economy to study transition dynamics during a disinflation. We experimented with different assumptions regarding the way that expectations are formed (rational versus adaptive) and the degree of central bank credibility (full versus partial) to determine which of the various specifications can best account for the trend movements in U.S. macro variables during the Volcker disinflation of the early 1980s. In our view, the Volcker episode represents a unique natural experiment that provides some valuable insight into the workings of the monetary transmission mechanism.

Our numerical simulations yielded three principle results. First, the introduction of slowly adjusting inflation forecasts due to adaptive expectations and partial credibility can help the model to capture the behavior of U.S. nominal interest rates during the 1979-1982 period. Second, a central bank may face diminishing returns in its efforts to enhance credibility. Third, the total welfare gains from achieving full credibility are likely to be small.

As a caveat to the interpretation of our results, we note that the economic circumstances which influenced expectations and credibility during the Volcker era would appear to be very different from those that prevail today. This fundamentally complicates the design of a macroeconomic model that can help us to predict the consequences of future monetary policy actions. 


\section{A Appendix}

This appendix describes our procedure for translating the sequence of real output gaps into a welfare cost measure based on utility maximization principles. We begin by postulating an economy where an infinitely-lived representative household supplies one unit of labor inelastically each period and maximizes

$$
V=E_{0} \sum_{t=0}^{\infty} \beta^{t} \ln c_{t}
$$

subject to:

$$
c_{t}+k_{t+1}=\underbrace{e^{\mu t+z_{t}} k_{t}^{\theta}}_{y_{t}}, \quad k_{0} \text { given, }
$$

where $\beta \in(0,1)$ is the quarterly discount factor, $c_{t}$ is real consumption, $k_{t}$ is the household's capital stock (which depreciates completely each period), $\mu \geq 0$ is the deterministic growth rate of technology, $z_{t}$ is a stationary stochastic shock (with an arbitrary law of motion), $y_{t}$ is per capita real output, and $\theta \in(0,1)$ is capital's output elasticity. The first-order condition for this problem is

$$
\frac{1}{c_{t}}=\beta E_{t} \frac{1}{c_{t+1}} \underbrace{\frac{\theta y_{t+1}}{k_{t+1}}}_{1+q_{t+1}},
$$

where we define $q_{t}$ as the quarterly real rate of interest. ${ }^{59}$ Solving (A.2) and (A.3) under the assumption of rational expectations yields the optimal decision rules: $c_{t}=(1-\theta \beta) y_{t}$ and $k_{t+1}=\theta \beta y_{t}$. These decision rules imply that households consume and save constant fractions of their current-period income. ${ }^{60}$

Defining $\tilde{y}_{t}$ as the deviation of log output from its linear trend implies $y_{t}=e^{\mu t+\tilde{y}_{t}}$, where we choose $k_{0}$ such that $y_{0}=1$. The household's optimal consumption decision can thus be expressed as $c_{t}=(1-\theta \beta) e^{\mu t+\tilde{y}_{t}}$. Substituting this expression for $c_{t}$ into (A.1) yields

$$
V=E_{0} \sum_{t=0}^{\infty} \beta^{t}\left[\ln (1-\theta \beta)+\mu t+\tilde{y}_{t}\right]
$$

\footnotetext{
${ }^{59}$ This definition follows directly from the first-order condition for privately-issued real bonds (which exist in zero-net supply). The capital rental rate is given by $1+q_{t}$.

${ }^{60}$ In an empirical study of aggregate U.S. consumption, Campbell and Mankiw (1989) estimate that about 50 percent of income accrues to "rule-of-thumb" agents whose consumption decisions depend soley on currentperiod income.
} 


$$
=\frac{\ln (1-\theta \beta)}{1-\beta}+\frac{\mu \beta}{(1-\beta)^{2}}+E_{0} \sum_{t=0}^{\infty} \beta^{t} \tilde{y}_{t} .
$$

Now consider an alternative benchmark economy with no fluctuations whatsoever such that $\tilde{y}_{t}=0$ for all $t$. Lifetime utility in the benchmark economy (denoted by $\bar{V}$ ) is simply given by the first two terms in (A.5). We wish to determine the constant percentage amount by which $c_{t}$ must be increased in the fluctuating economy to bring lifetime utility up to $\bar{V}$. Hence, we solve for $x$ such that

$$
\begin{aligned}
\bar{V} & =E_{0} \sum_{t=0}^{\infty} \beta^{t} \ln \left[c_{t}(1+x)\right] \\
& =V+\frac{\ln (1+x)}{1-\beta}
\end{aligned}
$$

The solution to (A.7) is $x=\exp [(\bar{V}-V)(1-\beta)]-1$. From equation (A.5), we have $\bar{V}-V=-E_{0} \sum_{t=0}^{\infty} \beta^{t} \tilde{y}_{t}$. Together, these expressions imply that our welfare cost measure can be written as

$$
\Delta W=100 x=100\left\{\exp \left[\left(-E_{0} \sum_{t=0}^{\infty} \beta^{t} \tilde{y}_{t}\right)(1-\beta)\right]-1\right\} .
$$

Equation (A.8) differs slightly from (21) in that we drop $E_{0}$ (since our simulations are deterministic) and we use 2000 periods to approximate the infinite horizon.

We calibrate $\beta$ using the balanced-growth version of equation (A.3). This implies $\beta=$ $\exp [\mu-\ln (1+\bar{q})]$. Taking $\mu=0.00373$ (based on an average annual growth rate in per capita real GDP of $1.5 \%$ ) and $\bar{q}=0.00496$ (based on an annual real rate of $\bar{\rho}=2 \%$ ), we obtain the value $\beta=0.99878$. 


\section{References}

[1] Akhtar, M.A. (1995). "Monetary Policy and Long-Term Nominal Interest Rates: A Survey of the Empirical Literature," Contemporary Economic Policy, 13, 110-130.

[2] Anderson, T.W. (1958). An Introduction to Multivariate Statistical Analysis. New York: John Wiley \& Sons Inc.

[3] Andolfatto, David and Paul Gomme. (1997). "Monetary Policy Regimes and Beliefs," Federal Reserve Bank of Minneapolis, Discussion Paper 118.

[4] Backus, David and John Driffill. (1985a). "Inflation and Reputation," American Economic Review, 75, 530-538.

[5] Backus, David and John Driffill. (1985b). "Rational Expectations and Policy Credibility Following a Change in Regime," Review of Economic Studies, 52, 211-221.

[6] Ball, Laurence. (1994). "What Determines the Sacrifice Ratio?" in N.G. Mankiw, ed., Monetary Policy. Chicago: University of Chicago Press.

[7] Ball, Laurence. (1995). "Disinflation with Imperfect Credibility," Journal of Monetary Economics, 35, 5-23.

[8] Barro, Robert J. (1976). "Rational Expectations and the Role of Monetary Policy," Journal of Monetary Economics, 2, 1-32.

[9] Barro, Robert J. (1986). "Reputation in a Model of Monetary Policy with Incomplete Information," Journal of Monetary Economics, 17, 3-20.

[10] Baxter, Marianne. (1985). "The Role of Expectations in Stabilization Policy," Journal of Monetary Economics, 15, 343-362.

[11] Baxter, Marianne.(1989). "Rational Response to Unprecedented Policies: The 1979 Change in Federal Reserve Operating Procedures," Carnegie-Rochester Conference Series on Public Policy, 31, 247-296.

[12] Bernanke, Ben S., Mark Gertler, and Mark Watson. (1997). "Systematic Monetary Policy and the Effects of Oil Price Shocks," Brookings Papers on Economic Activity, 1, 91-157.

[13] Bernanke, Ben S. and Ilian Mihov. (1998). "The Liquidity Effect and Long-Run Neutrality," Carnegie-Rochester Conference Series on Public Policy, 49, 149-194.

[14] Bertocchi, Graziella and Michael Spagat. (1993). "Learning, Experimentation, and Monetary Policy," Journal of Monetary Economics, 32, 169-183.

[15] Blackburn, Keith and Michael Christensen. (1989). "Monetary Policy and Credibility: Theories and Evidence," Journal of Economic Literature, 27, 1-45.

[16] Blake, Andrew P. and Peter F. Westaway. (1996). "Credibility and the Effectiveness of Inflation Targeting Regimes," The Manchester School Supplement, 64, 28-50.

[17] Blanchard, Olivier J. (1984). "The Lucas Critique and the Volcker Deflation," American Economic Association, Papers and Proceedings, 74, 211-215.

[18] Bomfim, Antulio N., Robert Tetlow, Peter von zur Muehlen, and John Williams. (1997). "Expectations, Learning, and the Costs of Disinflation: Experiments Using the FRB/US Model," Federal Reserve Board, Finance and Economics Discussion Series Paper 1997-42. 
[19] Bomfim, Antulio N. and Glenn D. Rudebusch. (1997). "Opportunistic and Deliberate Disinflation Under Imperfect Credibility," Federal Reserve Bank of San Francisco, Working Paper 97-07.

[20] Boschen, John F. and Charles L. Weise. (1996). "The Ex Ante Credibility of Disinflation Policy and the Cost of Reducing Inflation," College of William and Mary, unpublished manuscript.

[21] Brayton Flint, Eileen Mauskoupf, David Reifschneider, Peter Tinsley, and John Williams. (1997). "The Role of Expectations in the FRB/US Model," Federal Reserve Bulletin, 83, $227-245$.

[22] Buiter, Willem H., and Ian Jewitt. (1981). "Staggered Wage Setting with Real Wage Relativities: Variations on a Theme of Taylor," The Manchester School, 49, 211-228.

[23] Campbell, John Y. and N. Gregory Mankiw. (1989). "Consumption, Income, and Interest Rates: Reinterpreting the Time Series Evidence," in O.J. Blanchard and S. Fischer, eds., NBER Macroeconomics Annual, Volume 4. Cambridge MA: MIT Press.

[24] Chow, Gregory C. (1989). "Rational versus Adaptive Expectations in Present Value Models," Review of Economics and Statistics, 71, 385-393.

[25] Christiano, Lawrence J. and Martin Eichenbaum. (1992). "Liquidity Effects and the Monetary Transmission Mechanism," American Economic Association, Papers and Proceedings, 82, 346-353.

[26] Cook, Timothy. (1989). "Determinants of the Federal Funds Rate: 1979-1982," Federal Reserve Bank of Richmond, Economic Quarterly, 75(1), 3-19.

[27] Cook, Timothy and Thomas Hahn. (1989). "The Effect of Changes in the Federal Funds Rate Target on Market Interest Rates in the 1970s," Journal of Monetary Economics, 24, $331-351$.

[28] Cripps, Martin. (1991). "Learning Rational Expectations in a Policy Game," Journal of Economic Dynamics and Control, 15, 297-315.

[29] Cukierman Alex and Allan H. Meltzer. (1986). "A Theory of Ambiguity, Credibility, and Inflation Under Asymmetric Information," Econometrica, 54, 1099-1128.

[30] Evans, Charles L. and David A. Marshall. (1998). "Monetary Policy and the Term Structure of Nominal Interest Rates: Evidence and Theory," Carnegie-Rochester Conference Series on Public Policy, 49, 53-111.

[31] Evans, Martin and Karen K. Lewis. (1995). "Do Expected Shifts in Inflation Policy Affect Estimates of the Long-Run Fisher Relation?" Journal of Finance, 50, 225-253.

[32] Evans, Martin and Paul Wachtel. (1993). "Inflation Regimes and the Sources of Inflation Uncertainty," Journal of Money Credit and Banking, 25, 475-511.

[33] Fisher, Stanley. (1986). "Contracts, Credibility, and Disinflation," in S. Fisher, ed., Indexing, Inflation, and Economic Policy. Cambridge, MA: MIT Press.

[34] Flood, Robert P. and Peter M. Garber. (1980). "An Economic Theory of Monetary Reform," Journal of Political Economy, 88, 24-58.

[35] Friedman, Milton. (1968). "The Role of Monetary Policy," American Economic Review, $58,1-17$.

[36] Friedman, Milton. (1984). "Lessons from the 1979-82 Monetary Policy Experiment," American Economic Association, Papers and Proceedings, 74, 397-400. 
[37] Friedman, Benjamin M. (1979). "Optimal Expectations and the Extreme Information Assumptions of Rational Expectations Models," Journal of Monetary Economics, 5, 2341.

[38] Fuhrer Jeffrey C. (1994). "Optimal Monetary Policy and the Sacrifice Ratio," in Goals, Guidelines, and Constraints Facing Monetary Policymakers, Proceedings of a Conference Sponsored by the Federal Reserve Bank of Boston.

[39] Fuhrer Jeffrey C. (1996). "Monetary Policy Shifts and Long-Term Interest Rates," Quarterly Journal of Economics, 111, 1183-1209.

[40] Fuhrer Jeffrey C. (1997a). "Towards a Compact, Empirically-Verified Rational Expectations Model for Monetary Policy Analysis," Carnegie-Rochester Conference Series on Public Policy, 47, 197-230.

[41] Fuhrer Jeffrey C. (1997b). "The (Un)Importance of Forward-Looking Behavior in Price Specifications," Journal of Money Credit and Banking, 29, 338-350.

[42] Fuhrer Jeffrey C and Mark A. Hooker. (1993). "Learning About Monetary Regime Shifts in an Overlapping Wage Contract Model," Journal of Economic Dynamics and Control, $17,531-553$.

[43] Fuhrer Jeffrey C and George Moore. (1995a). "Inflation Persistence," Quarterly Journal of Economics, 110, 127-160.

[44] Fuhrer Jeffrey C and George Moore. (1995b). Monetary Policy Trade-offs and the Correlation between Nominal Interest Rates and Real Output," American Economic Review, 85, 219-239.

[45] Gagnon, Joseph H. (1997). "Inflation Regimes and Inflation Expectations," Federal Reserve Board, International Finance Discussion Paper 581.

[46] Goodfriend, Marvin. (1993). "Interest Rate Policy and the Inflation Scare Problem: 19791992," Federal Reserve Bank of Richmond, Economic Quarterly, 79(1), 1-24.

[47] Gordon, Robert J. and Stephen King. (1982). "The Output Cost of Disinflation in Traditional and Vector Autoregressive Models," Brookings Papers on Economic Activity, 1, 205-244.

[48] Hafer, R. W. (1983). "Weekly Money Supply Forecasts: Effects of the October 1979 Change in Monetary Control Procedures," Federal Reserve Bank of St. Louis, Review, 65, April, 26-32.

[49] Hardouvelis, Gikas A. and Scott W. Barnhart. (1989). "The Evolution of Federal Reserve Credibility: 1978-1984," Review of Economics and Statistics, 71, 385-393.

[50] Hetzel, Robert L. (1986). "Monetary Policy in the Early 1980s," Federal Reserve Bank of Richmond, Economic Review, 72(2), 20-32.

[51] Hodrick, Robert J. and Edward C. Prescott. (1997). "Postwar U.S. Business Cycles: An Empirical Investigation," Journal of Money, Credit, and Banking, 29, 1-16.

[52] Huh, Chan G. and Kevin J. Lansing. (1998). "Federal Reserve Credibility and Inflation Scares," Federal Reserve Bank of San Francisco, Economic Review, 98(2), 3-16.

[53] İmrohoroğlu, Ayse. (1989). "Cost of Business Cycles with Indivisibilities and Liquidity Constraints," Journal of Political Economy, 97, 1364-1383.

[54] Ireland, Peter N. (1995). "Optimal Disinflationary Paths," Journal of Economic Dynamics and Control, 19, 1429-1448. 
[55] Judd, John P. and Glenn D. Rudebusch. (1998). "Taylor's Rule and the Fed : 1970-1997," Federal Reserve Bank of San Francisco, Economic Review, 98(3), 3-16.

[56] Kiley, Michael T. (1998). "Monetary Policy under Neoclassical and New-Keynesian Phillips Curves, with an Application to Price Level and Inflation Targeting," Federal Reserve Board, Finance and Economics Discussion Series Paper 1998-27.

[57] King, Mervyn. (1996). "How Should Central Banks Reduce Inflation?-Conceptual Issues," in Achieving Price Stability, A Symposium Sponsored by The Federal Reserve Bank of Kansas City.

[58] King, Robert G. and Mark W. Watson. (1994). "The Post-War U.S. Phillips Curve: A Revisionist Econometric History," Carnegie-Rochester Conference Series on Public Policy, $41,157-219$.

[59] King, Robert G. and Mark W. Watson. (1996). "Money, Prices, Interest Rates, and The Business Cycle," Review of Economics and Statistics, 58, 35-53.

[60] Lewis, Karen K. (1989). "Changing Beliefs and Systematic Rational Forecast Errors with Evidence from Foreign Exchange," American Economic Review, 79, 621-636.

[61] Lovell, Michael C. (1986). "Tests of the Rational Expectations Hypothesis," American Economic Review, 76, 110-124.

[62] Lucas, Robert E., Jr. (1972). "Expectations and the Neutrality of Money," Journal of Economic Theory, 4, 103-124.

[63] Lucas, Robert E., Jr. (1973). "Some International Evidence on Output-Inflation Tradeoffs," American Economic Review, 63, 326-344.

[64] Lucas, Robert E., Jr. (1976). "Econometric Policy Evaluation: A Critique," CarnegieRochester Conference Series on Public Policy, 1, 19-46.

[65] Lucas, Robert E., Jr. (1987). Models of Business Cycles. Oxford: Basil Blackwell.

[66] Mankiw, N. Gregory. (1994). Discussion of "Optimal Monetary Policy and the Sacrifice Ratio," in Goals, Guidelines, and Constraints Facing Monetary Policymakers, Proceedings of a Conference Sponsored by the Federal Reserve Bank of Boston.

[67] Mankiw, N. Gregory. (1997). Macroeconomics, Third Edition. New York: Worth Publishers.

[68] Marcet, Albert and Thomas J. Sargent. (1989). "Convergence of Least Squares Learning Mechanisms in Self-Referential Linear Stochastic Models," Journal of Economic Theory, $48,337-368$.

[69] Marcet, Albert and Juan Pablo Nicolini. (1997). "Recurrent Hyperinflations and Learning," University of Pompeu Fabra, unpublished manuscript.

[70] Meyer, Laurence H. and Charles Webster, Jr. (1982). "Monetary Policy and Rational Expectations: A Comparison of Least Squares and Bayesian Learning," Carnegie-Rochester Conference Series on Public Policy, 17, 67-98.

[71] Ohanian, Lee E. and Alan C. Stockman. (1995). "Theoretical Issues of Liquidity Effects," Federal Reserve Bank of St. Louis, Review, 77(3), 3-25.

[72] Orphanides, Athanasios, David. H. Small, Volker Wieland, and David W. Wilcox. (1997). "A Quantitative Exploration of the Opportunistic Approach to Disinflation," Federal Reserve Board, Finance and Economics Discussion Series Paper 1997-36. 
[73] Pagan, Adrian R. and John C. Robertson. (1995). "Resolving the Liquidity Effect," Federal Reserve Bank of St. Louis, Review, 77(3), 33-54.

[74] Phelps, Edmund S. (1967). "Phillips Curves, Expectations of Inflation and Optimal Unemployment Over Time," Economica, 34, 254-281.

[75] Phelps, Edmund S. (1968). "Money-Wage Dynamics and Labor Market Equilibrium," Journal of Political Economy, 76, 678-711.

[76] Roberts, John. (1997). "Is Inflation Sticky?" Journal of Monetary Economics, 39, 173196.

[77] Romer, Christina D. and David H. Romer. (1989). "Does Monetary Policy Matter? A New Test in the Spirit of Friedman and Schwartz," in O.J. Blanchard and S. Fischer, eds., NBER Macroeconomics Annual, Volume 4. Cambridge MA: MIT Press.

[78] Romer, Christina D. and David H. Romer. (1994). "Monetary Policy Matters," Journal of Monetary Economics, 34, 75-88.

[79] Romer, Christina D. and David H. Romer. (1997). "Institutions for Monetary Stability," in C. Romer and D. Romer, eds., Reducing Inflation: Motivation and Strategy. Chicago: University of Chicago Press.

[80] Ruge-Murcia, Francisco J. (1995). "Credibility and Changes in Policy Regime," Journal of Political Economy, 103, 176-208.

[81] Sargent, Thomas J. (1973). "Rational Expectations, the Real Rate of Interest, and the Natural Rate of Unemployment," Brookings Papers on Economic Activity, 43, 429-472.

[82] Sargent, Thomas J. (1982). "The Ends of Four Big Inflations," in R.E. Hall, ed., Inflation: Causes and Effects. Chicago: University of Chicago Press.

[83] Sargent, Thomas J. (1983). "Stopping Moderate Inflations: The Methods of Poincaré and Thatcher," in R. Dornbusch and M.H. Simonsen, eds., Inflation, Debt, and Indexation, Cambridge, MA: MIT Press.

[84] Sargent, Thomas J. (1993). Bounded Rationality in Economics. Oxford: Oxford University Press.

[85] Sargent, Thomas J. (1999). The Conquest of American Inflation. Princeton: Princeton University Press.

[86] Sargent, Thomas J and Neil Wallace. (1975). "Rational Expectations, the Optimal Monetary Instrument, and the Optimal Money Supply Rule," Journal of Political Economy, $83,241-254$.

[87] Shapiro, Matthew D. (1994). "Federal Reserve Policy: Cause and Effect," in N.G. Mankiw, ed., Monetary Policy. Chicago: University of Chicago Press.

[88] Taylor, John B. (1975). "Monetary Policy During a Transition to Rational Expectations," Journal of Political Economy, 83, 1009-1021.

[89] Taylor, John B. (1980). "Aggregate Dynamics and Staggered Contracts," Journal of Political Economy, 88, 1-23.

[90] Taylor, John B. (1982). "Establishing Credibility: A Rational Expectations Viewpoint," American Economic Association, Papers and Proceedings, 74, 207-210.

[91] Taylor, John B. (1983). "Union Wage Settlements During a Disinflation," American Economic Review, 73, 981-993. 
[92] Taylor, John B. (1993). "Discretion versus Policy Rules in Practice," Carnegie-Rochester Conference Series on Public Policy, 39, 195-214.

[93] Taylor, John B. (1999). "A Historical Analysis of Monetary Policy Rules," in J.B. Taylor, ed., Monetary Policy Rules. Chicago: University of Chicago Press.

[94] Tetlow, Robert J. and Peter von zur Muehlen. (1999). "Simplicity versus Optimality: The Choice of Monetary Policy When Agents Must Learn," Federal Reserve Board, Finance and Economics Discussion Series Paper 1999-10.

[95] Volcker, Paul A. (1979). "Statement" before the Joint Economic Committee, Federal Reserve Bulletin, 65 (November), 888-890.

[96] Walsh, Carl E. (1988). "Testing for Real Effects of Monetary Policy Regime Shifts," Journal of Money Credit and Banking, 20, 393-401. 

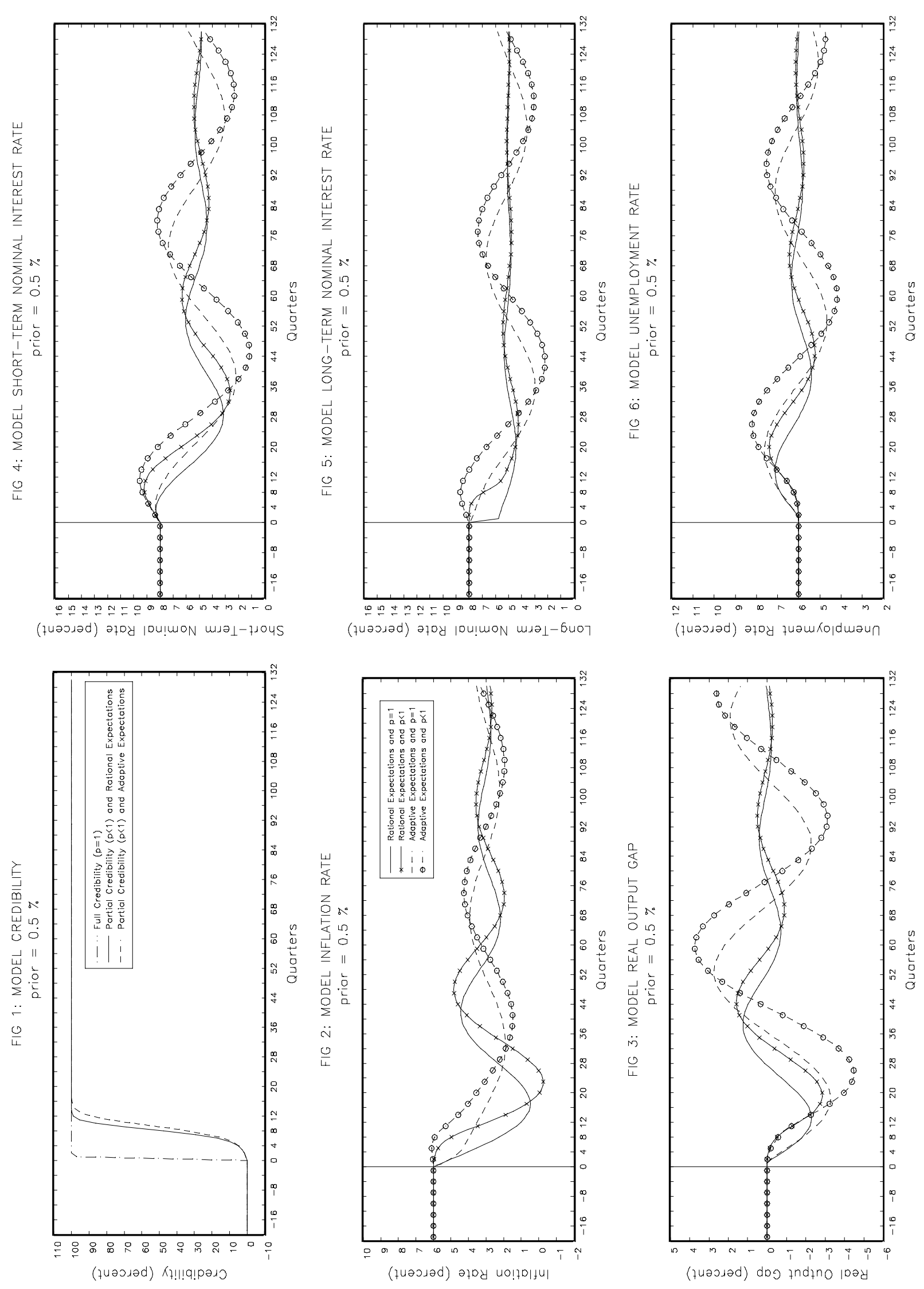


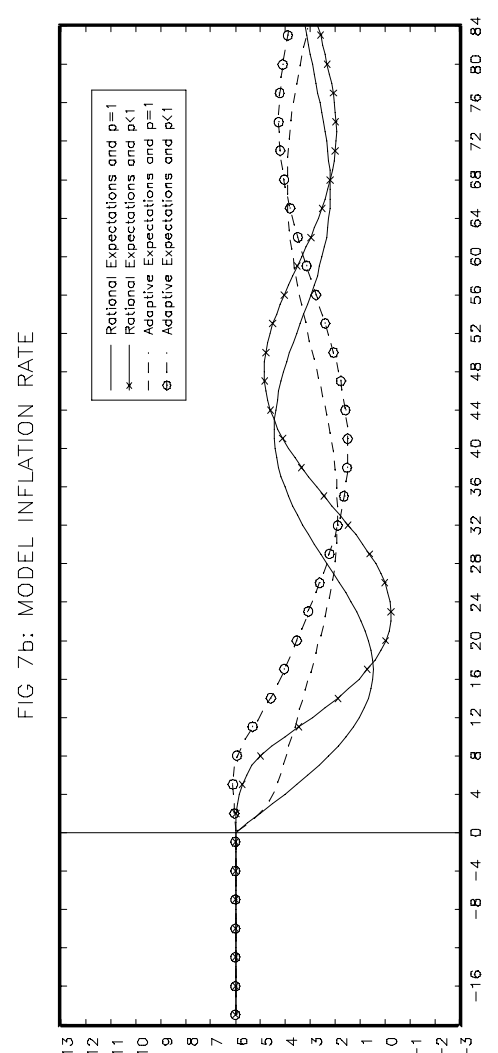

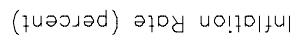

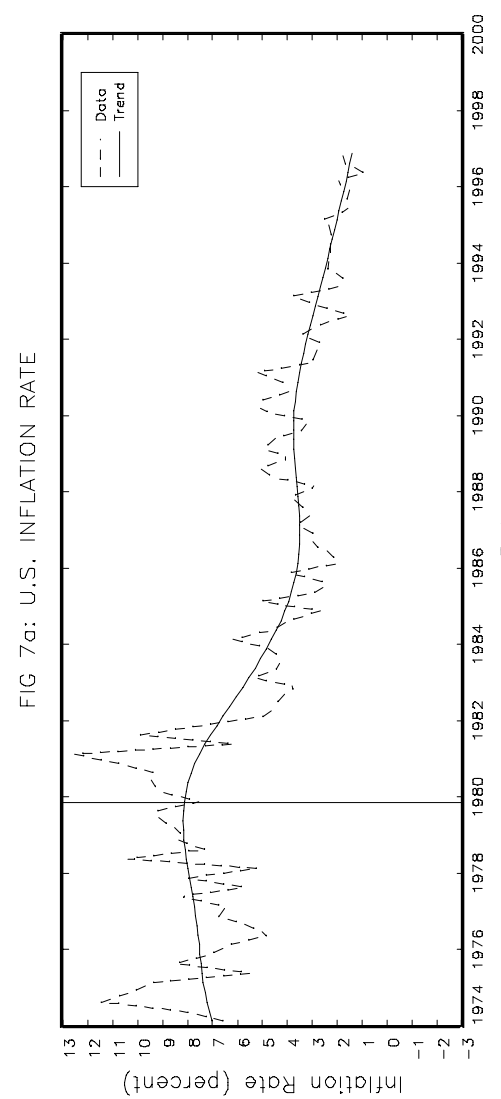

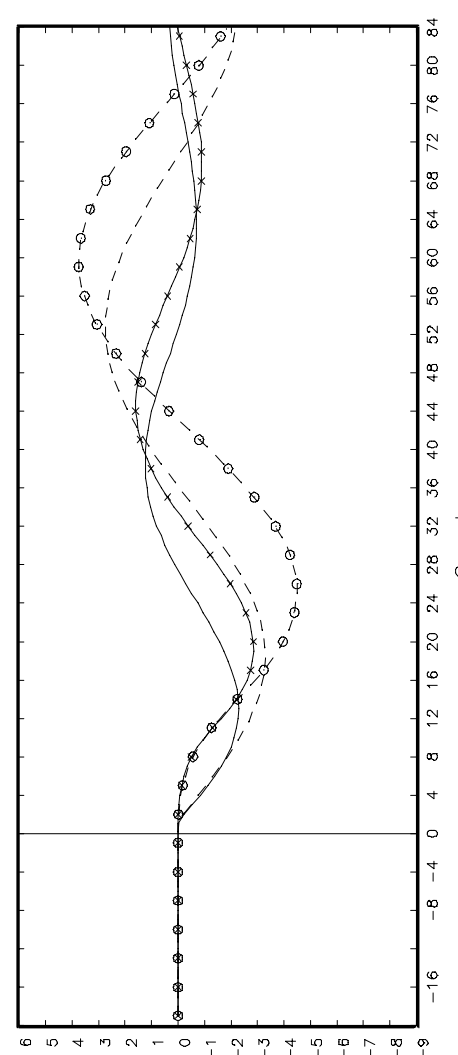

(zuәวגәd) dog zndzno poəy

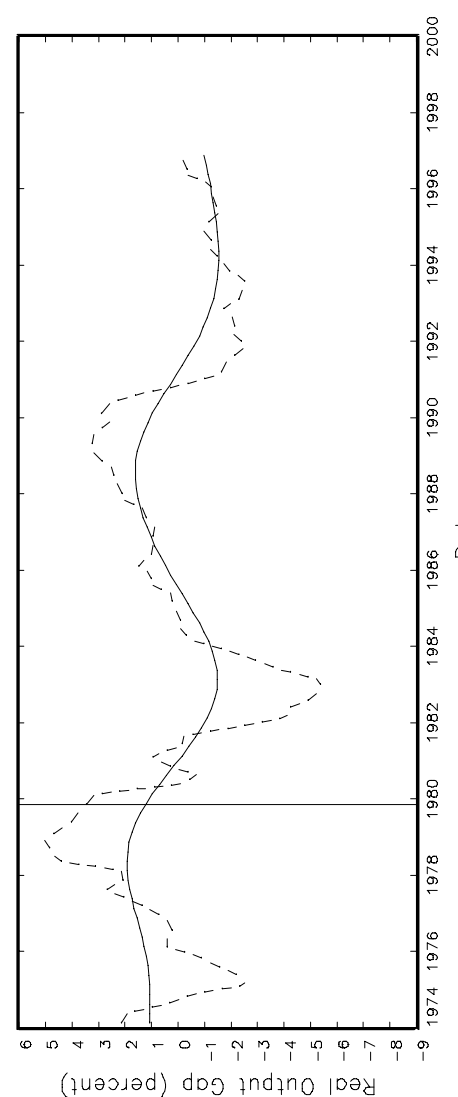

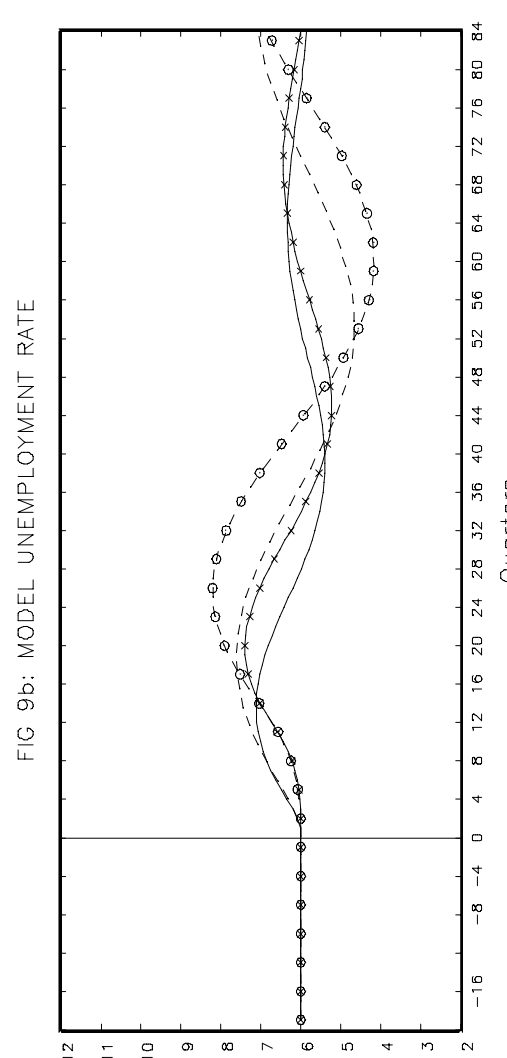

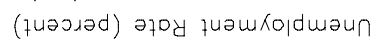

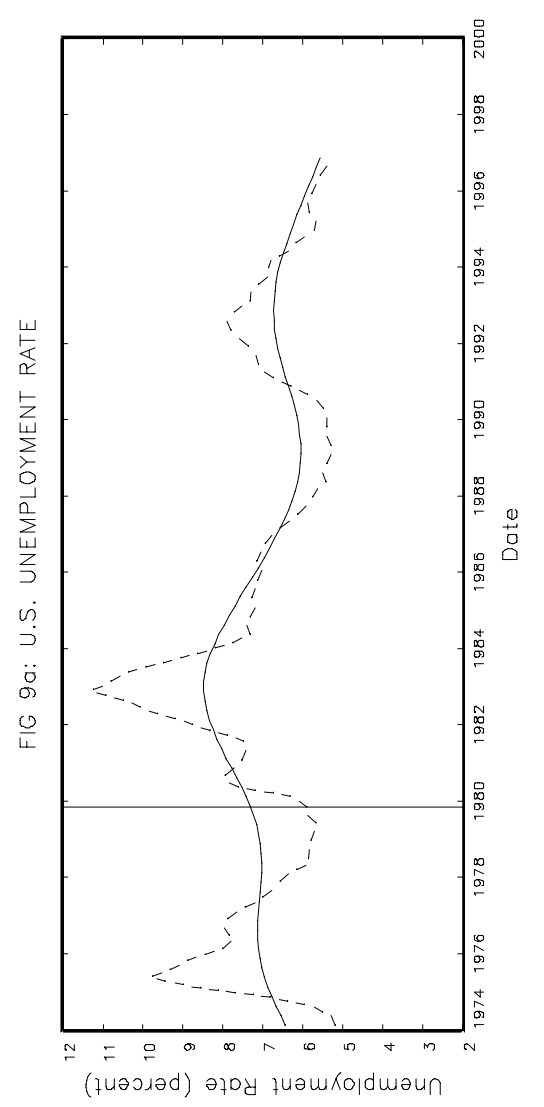



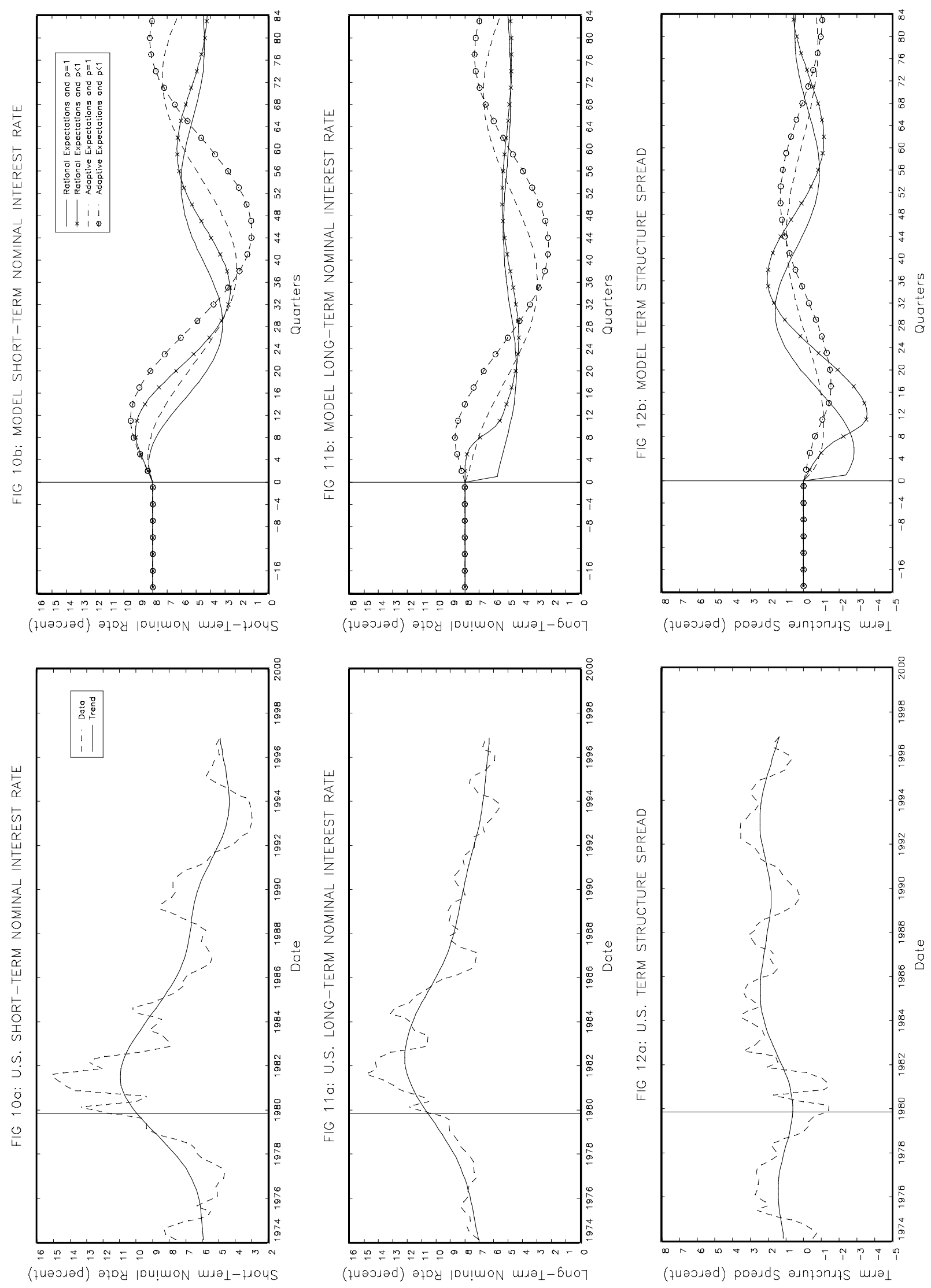

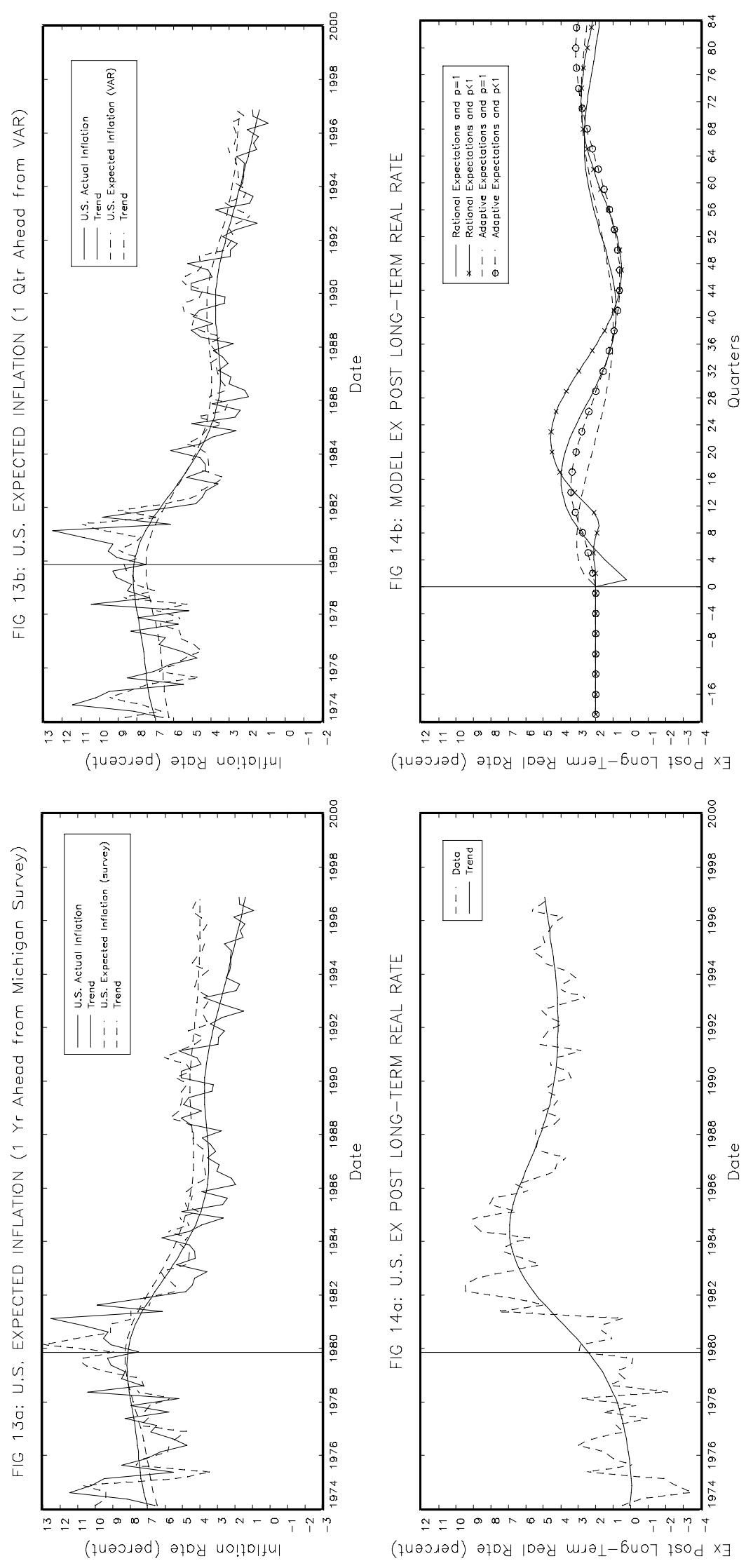

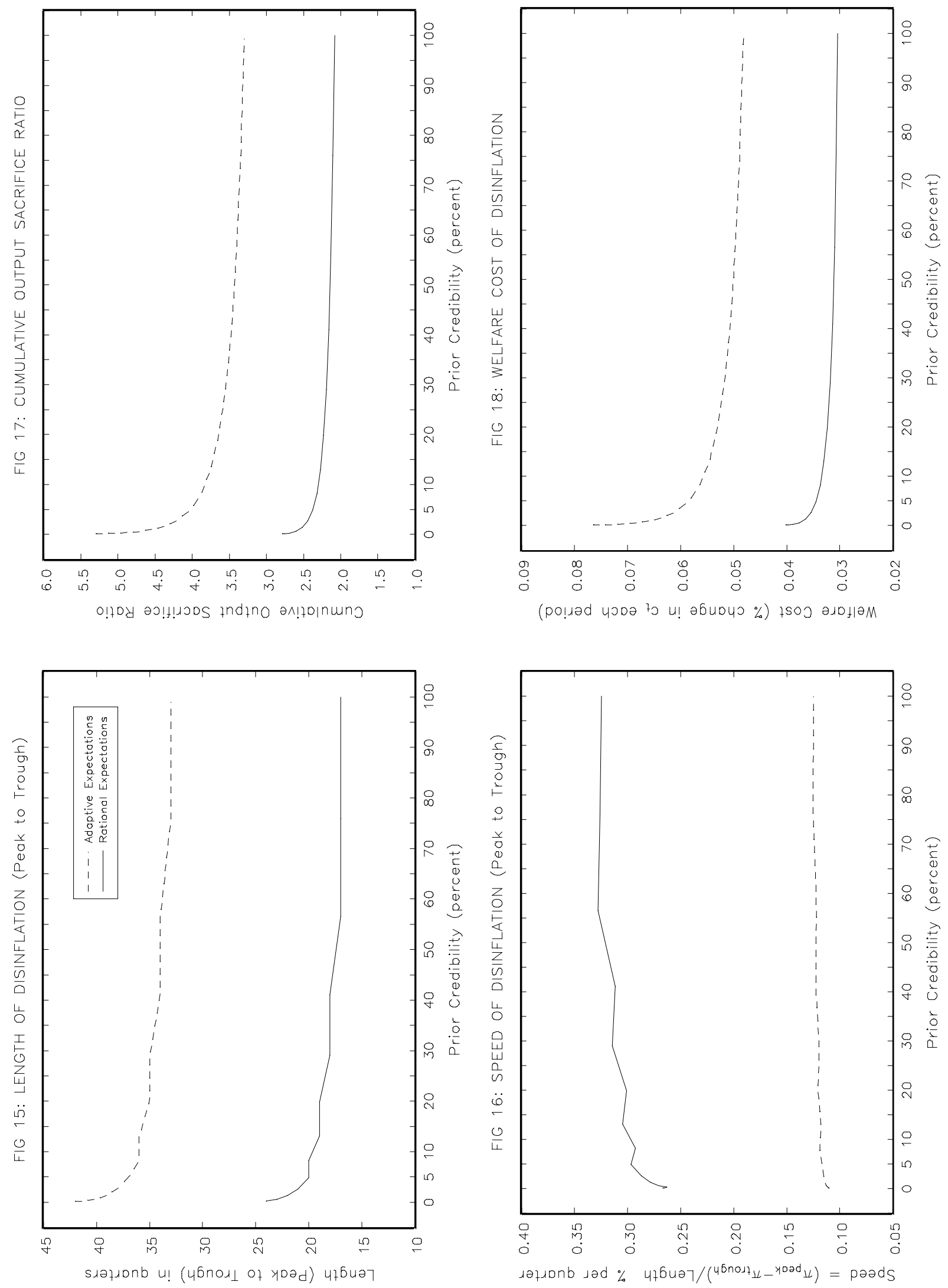